\title{
Clinical significance and mechanisms associated with segmental UPD
}

\author{
Peter R. Papenhausen ${ }^{1}$, Carla A. Kelly' , Samuel Harris², Samantha Caldwell', Stuart Schwartz' and \\ Andrea Penton ${ }^{1 *}$ (i)
}

\begin{abstract}
Whole chromosome uniparental disomy (UPD) has been well documented with mechanisms largely understood. However, the etiology of segmental limited UPD (segUPD) is not as clear. In a 10-year period of confirming (>300) cases of whole chromosome UPD, we identified 86 segmental cases in both prenatal and postnatal samples. Thirtytwo of these cases showed mosaic segmental UPD at $11 p$ due to somatic selection associated with Beckwith-Wiedemann syndrome. This study focuses on apparent mechanisms associated with the remaining cases, many of which appear to represent corrections of genomic imbalance such as deletions and derivative chromosomes. In some cases, segmental UPD was associated with the generation of additional genomic imbalance while in others it apparently resulted in restoration of euploidy. Multiple tests utilizing noninvasive prenatal testing (NIPT), chorionic villus sampling (CVS) and amniotic fluid samples from the same pregnancy revealed temporal evidence of correction and a "hotspot" at $1 p$. Although in many cases the genomic imbalance was dosage "repaired" in the analyzed tissue, clinical effects could be sustained due to early developmental effects of the original imbalance or due to its continued existence in other tissues. In addition, if correction did not occur in the gametes there would be recurrence risks for the offspring of those individuals. Familial microarray allele patterns are presented that differentiate lack of gamete correction from somatic derived gonadal mosaicism. These results suggest that the incidence of segUPD mediated correction is underestimated and may explain the etiology of some clinical phenotypes which are undetected by routine microarray analysis and many exome sequencing studies.
\end{abstract}

Keywords: Uniparental disomy, Segmental uniparental disomy, Mitotic correction, Chromosome microarray (CMA), Cytogenetics, Homologous recombination

\section{Background}

Whole chromosome uniparental disomy (UPD), the inheritance of both homologues from one parent, has been confirmed as primarily originating from somatic corrections of meiotically-derived trisomy or monosomy [1]. Uniparental heterodisomy is the inheritance of different chromosome homologues from one parent, while uniparental isodisomy is the inheritance of two copies of

*Correspondence: pentona@labcorp.com

${ }^{1}$ Cytogenetics Department, Laboratory Corporation of America, Research Triangle Park, NC 27709, USA

Full list of author information is available at the end of the article a single chromosome homologue from one parent. Individuals with mixed UPD (mixUPD) have stretches of isodisomic segments and heterodisomic segments because of meiotic recombination. Isodisomic segments are visible on SNP microarrays as extended runs of homozygosity $(\mathrm{ROH})$ and, in the absence of other chromosomes with extended $\mathrm{ROH}$ due to consanguinity, the isodisomic segments provide a distinct clue to the presence of UPD $[2,3]$.

Identification of UPD is clinically important because it can be accompanied by imprinting disorders, autosomal recessive disorders, or aberrant development due to the presence of transient aneusomy $[4,5]$. The incidence

(C) The Author(s) 2021. Open Access This article is licensed under a Creative Commons Attribution 4.0 International License, which permits use, sharing, adaptation, distribution and reproduction in any medium or format, as long as you give appropriate credit to the original author(s) and the source, provide a link to the Creative Commons licence, and indicate if changes were made. The images or other third party material in this article are included in the article's Creative Commons licence, unless indicated otherwise in a credit line to the material. If material is not included in the article's Creative Commons licence and your intended use is not permitted by statutory regulation or exceeds the permitted use, you will need to obtain permission directly from the copyright holder. To view a copy of this licence, visit http://creativecommons.org/licenses/by/4.0/. The Creative Commons Public Domain Dedication waiver (http://creativecommons.org/ publicdomain/zero/1.0/) applies to the data made available in this article, unless otherwise stated in a credit line to the data. 
of whole chromosome UPD has been estimated at 1 in 3500 newborns [6], but more recent molecular studies estimate the prevalence to be much greater at about $0.2-0.3 \%$ [7-9]. In contrast, reports of copy-neutral segmentally-restricted UPD are much rarer at about $0.03 \%$, excluding Beckwith-Wiedemann syndrome (BWS) cases associated with imprinted paternal growth advantage at $11 \mathrm{p} 15.5[10,11]$.

SegUPD is especially common in cancer and, in those studies, it is generally referred to as copy-neutral loss of heterozygosity $(\mathrm{CN}-\mathrm{LOH})$. The clonal evolution process resulting in $\mathrm{CN}-\mathrm{LOH}$ is based on selective proliferative advantage, primarily driven by loss of tumor suppressor genes or acquisition of homozygosity for oncogenic mutations [2]. Constitutional segUPD is typically detected in single nucleotide polymorphism (SNP) chromosomal microarray analysis (CMA) as a long terminal $\mathrm{ROH}$ in a single chromosome (Fig. 1) that, in molecular follow-up, shows allelic exclusions from one parent in the $\mathrm{ROH}$ and biparental allele inheritance in the rest of the chromosome. Consanguinity can present a diagnostic problem for detection of segUPD, but is associated with $\mathrm{ROH}$ in multiple chromosomes that are usually not found exclusively in terminal regions [12]. The American College of Medical Genetics has proposed guidelines for diagnostic testing of suspected whole chromosome UPD and segUPD [13].

The mechanism of origin of segUPD is different from that of whole chromosome UPD and thought to arise from homologous recombination due to interhomologue repair of double-stranded DNA breaks that occur somatically followed by subsequent clonal expansion of the recombinant cell [14] (Fig. 2). The homologue repair, thus, results in subpopulations with exclusive isoallelic segments that typically involve the terminal arm. DNA repair mechanisms that don't generate crossovers can result in interstitial regions of segUPD. There is evidence for these instances of segUPD described in two studies involving chromosome $14[15,16]$ and in the UPD database [17]. Interstitial segUPD, however, has not been detected in the previously mentioned sequence analysis of trios or in the current study. This may be due to the fact that short interstitial regions of segUPD, expected with DNA repair involving no crossovers, are not detected by the present sequencing algorithms and CMA criteria. In addition, there may be lack of selective pressure for a second recombination event necessary for interstitial segUPD when a first recombination event has corrected an imbalance.

Using high resolution CMA in this study, we have identified results consistent with either segUPD or apparent mosaic segUPD over a 10-year period. Although all nonmosaic cases were molecularly confirmed, the presence of normal cells resulted in inconclusive results in mosaic cases. The etiology and associated clinical significance of segUPD is the focus of this report, along with the importance of appropriate genetic counseling.

\section{Materials and methods}

DNA samples for microarray analysis were extracted either from placental cells, amniocytes, buccal cells or leukocytes using standard methods. DNA was digested with Nsp1, ligated to adaptors, and amplified using Titanium Taq with a GeneAmp PCR System 9700. PCR products were purified using AMPure beads and quantified using a NanoDrop 8000. Purified DNA was fragmented, biotin-labeled and hybridized to the Affymetrix $6.0^{\circledR}$ or Cytoscan HD chip ${ }^{\circledR}$ (Thermo Fisher Scientific). The two versions have $\sim 1.8$ million probes with $\sim 50 \%$ SNP targeting and $\sim 2.7$ million probes with $\sim 33 \%$ SNP targeting, respectively. The copy number state is indicated by either the Log2 signal intensity ratio tract (Log2(sample/

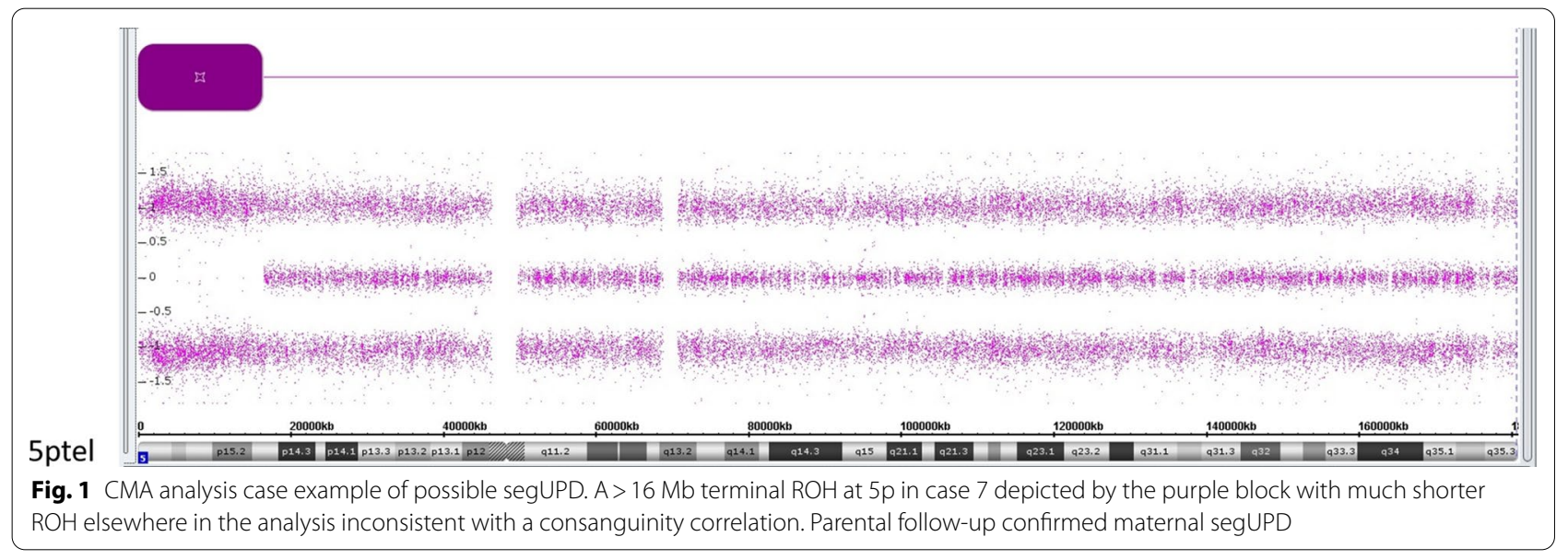




\section{Interhomologue HR}

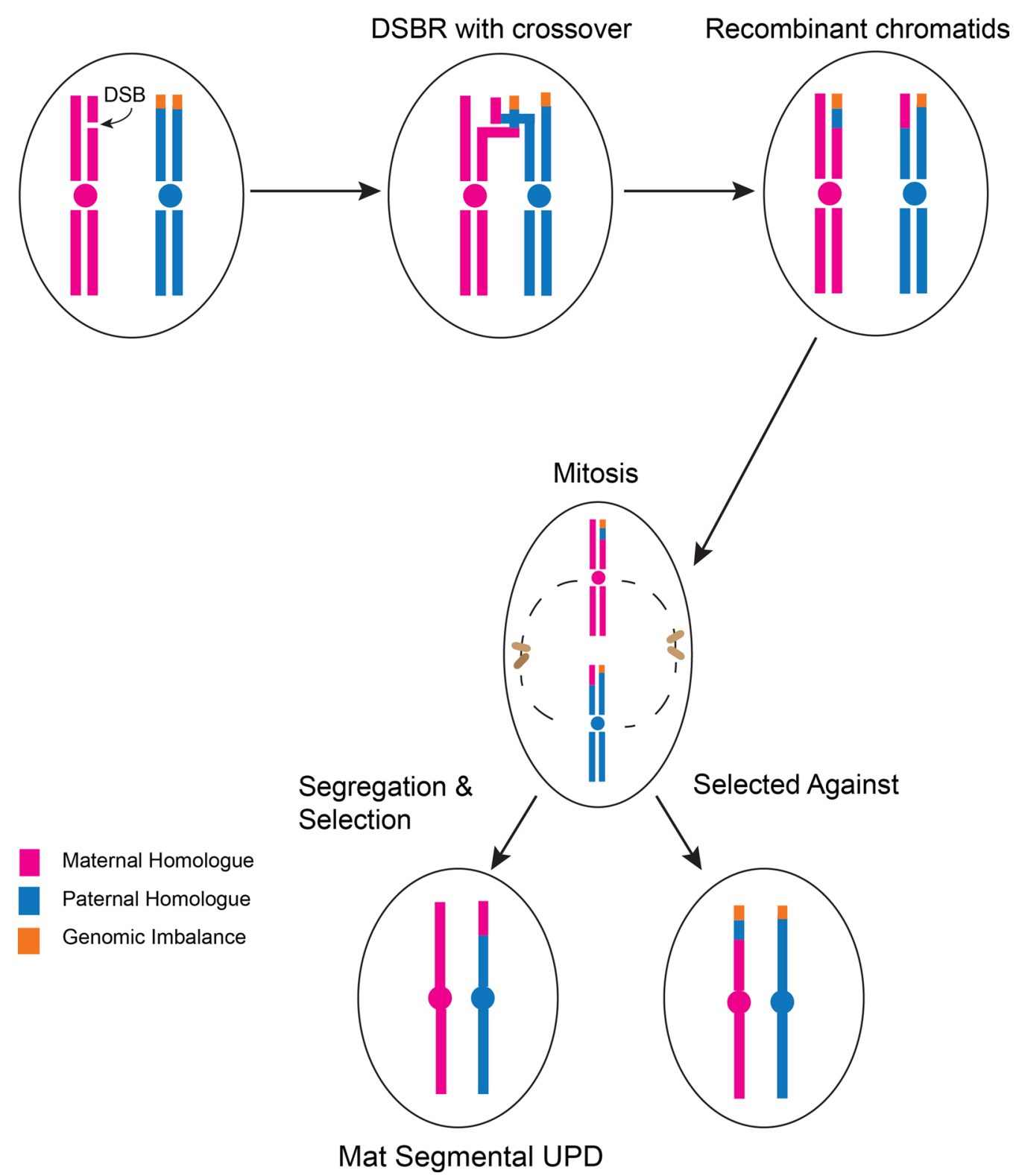

Fig. 2 Graphic depiction of mitotic-mediated correction of meiotically derived imbalance. Double-strand break mediated repair results in inter-homologue recombination during $\mathrm{S}$ phase of a diploid chromatid (pink) with a chromatid (blue) containing a terminal rearrangement (orange). This results in two chromosome homologues, each containing one recombinant chromatid. Subsequent mitotic segregation can result in two outcomes: two daughter cells that, like the parent cell, are heterozygous for the original imbalance or in the outcome described in the figure. In this case one daughter cell is homozygous for the imbalance and the other is euploid but with uniparental inheritance in the recombinant region, segUPD, detected as a terminal ROH in microarray testing. Survival and expansion are more likely for the euploid daughter cell. However, variable selective pressure, both in cancer and some constitutional alterations, can result in clonal expansion of cells with the imbalance post mitotic recombination

reference signal)) or the Smooth signal tract, a Gaussian smoothed calibrated copy number estimate. SNP genotypes are determined by the allele difference tract. Each probe corresponds to a unique genomic position and is visualized as a point in the $\log 2$ and allele difference tracts. Proprietary chromosome analysis suite software (CHAS) from Applied Biosytems was utilized for analysis 
of all microarray data in this study. The analysis was based on the GRCh37/hg19 assembly.

Based on laboratory empirical data and microarray validation studies, an extended ( $>8 \mathrm{Mb}$ ) terminal $\mathrm{ROH}$ in a single chromosome is the established cutoff that warrants confirmation of potential whole chromosome UPD or segUPD. Parental follow-up with region specific microsatellites or by trio CMA allele comparisons differentiates between potential UPD or an isolated region of shared parental ancestry. Multiple $(>2)$ parental exclusions along the whole chromosome defines whole chromosome UPD, while exclusions restricted to the homozygous segment defines segUPD. Terminal regions with mosaic segUPD are distinctive because they show four tracts, with the distance of the two inner tracts from the central line defining the percentage of the homozygous copy-neutral cell line (Fig. 3). Mosaic cases are likely to represent segUPD, but due to the admixture of cells with biparental alleles and the non-quantitative nature of microsatellite UPD testing, confirmation testing was not attempted. Quantitative pyrosequencing may be used for cases in which the parent of origin allelic dosage ratios need to be confirmed, but was not readily available.

Non-invasive prenatal testing (NIPT), a prenatal screen that analyzes cell free DNA (cfDNA) fragments in maternal plasma derived from the placental trophoblast, was performed by genome-wide massive parallel sequencing (MPSS), as per Jensen, 2013 (Sequenom, a wholly owned subsidiary of Laboratory Corporation of America) [18]. The test is usually performed from 13 to 20 weeks gestation and, though often used as an aneuploidy screen, higher resolution was available, which allowed detection of deletions and duplications $\geq 7 \mathrm{Mb}$ in the cases presented [19].

Fluorescence in situ hybridization (FISH), chromosome studies, and microsatellite analyses were performed using

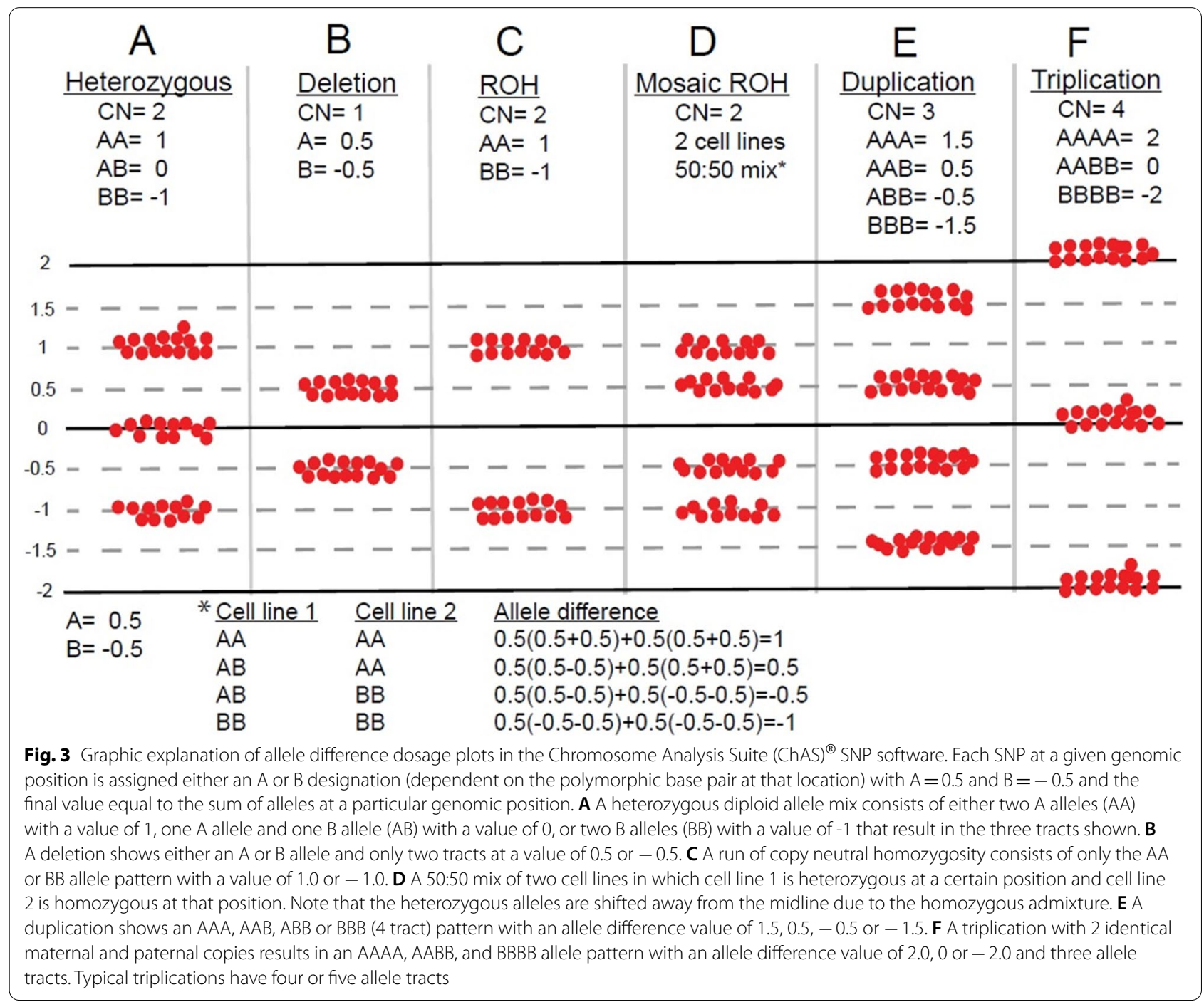


standard techniques. Appropriate informed consent was obtained from human subjects.

\section{Results}

A cohort of 85 cases was compiled for this study. More than a third $(32 / 85)$ of the cases of segUPD identified were associated with terminal mosaic $\mathrm{ROH}$ of various lengths and percentages on the $\mathrm{p}$ arm of chromosome 11 (Fig. 4), the phenotypes of which were consistent with BWS. The remaining 53 cases were grouped into three categories: those with non-mosaic terminal segUPD (14 cases-Table 1), those with mosaic terminal segUPD (22 cases-Table 2) and those with terminal segUPD contiguous with triplications (17 cases-Table 3 ).

This study offers evidence that segUPD has occurred secondarily to genomic corrections of deletions, derivative chromosomes, and terminal deletions contiguous with copy number gains. Specific examples of cases associated with various subcategories from the tables are highlighted as follows.

\section{SegUPD associated with corrections of derivative chromosomes}

Case 1 illustrates homologous recombination-based correction of an unbalanced derivative chromosome $1[\operatorname{der}(1) \mathrm{t}(1 ; 17)(\mathrm{p} 36.3 ; \mathrm{q} 21)]$ that was detected in 48 of 50 amniocyte metaphases from a 21.4 week pregnancy (Fig. 5A). The indication was choroid plexus cysts and the pregnancy was continued to term. Nine years later, the proband had a peripheral blood microarray study, due to a clinical phenotype of an ependymal cyst, abnormal electroencephalogram (EEG), global developmental delay, hearing impairment, precocious puberty, enuresis, and severe intellectual deficit. The CMA showed a nonmosaic 9.39 $\mathrm{Mb}$ terminal $\mathrm{ROH}$ initiating at $1 \mathrm{p} 36.22$ (Fig. 5B), with no evidence of a derivative-related deletion of $1 \mathrm{p}$ or partial trisomy of $17 \mathrm{p}$ (Fig. 5C). A concurrent G-band blood analysis was normal, with no evidence of the $\operatorname{der}(1) \mathrm{t}(1 ; 17)$ in 105 cells. A subsequent buccal microarray analysis showed the same $9.39 \mathrm{Mb} \mathrm{ROH}$ on $1 \mathrm{p}$, but again, no evidence of a residual derivative 1 imbalance. Parental chromosome analyses were normal and maternal SNP microarray comparisons were consistent with maternal segUPD in the $\mathrm{ROH}$ region. Thus, the results are consistent with a de novo paternal origin of the derivative chromosome 1 (Additional file 1: Figure S1).

The noninvasive prenatal testing (NIPT) result of case 3 showed a terminal deletion of $1 p$ and a duplication of terminal 1q equal to the fetal fraction at 14 weeks gestation, indicating an apparent non-mosaic fetal imbalance (Fig. 6A). This imbalance is consistent with the inheritance of a possible pericentric inversion recombinant of chromosome 1. A subsequent amniocyte CMA at 23 weeks showed no dosage changes of chromosome 1 , although a $21.58 \mathrm{Mb}$ terminal $1 \mathrm{p} \mathrm{ROH}$ was present enabling interpretation of the terminal $1 \mathrm{p} \mathrm{ROH}$ as apparent segUPD (Fig. 6B). Parental chromosome studies were recommended to rule out a recombinant chromosome

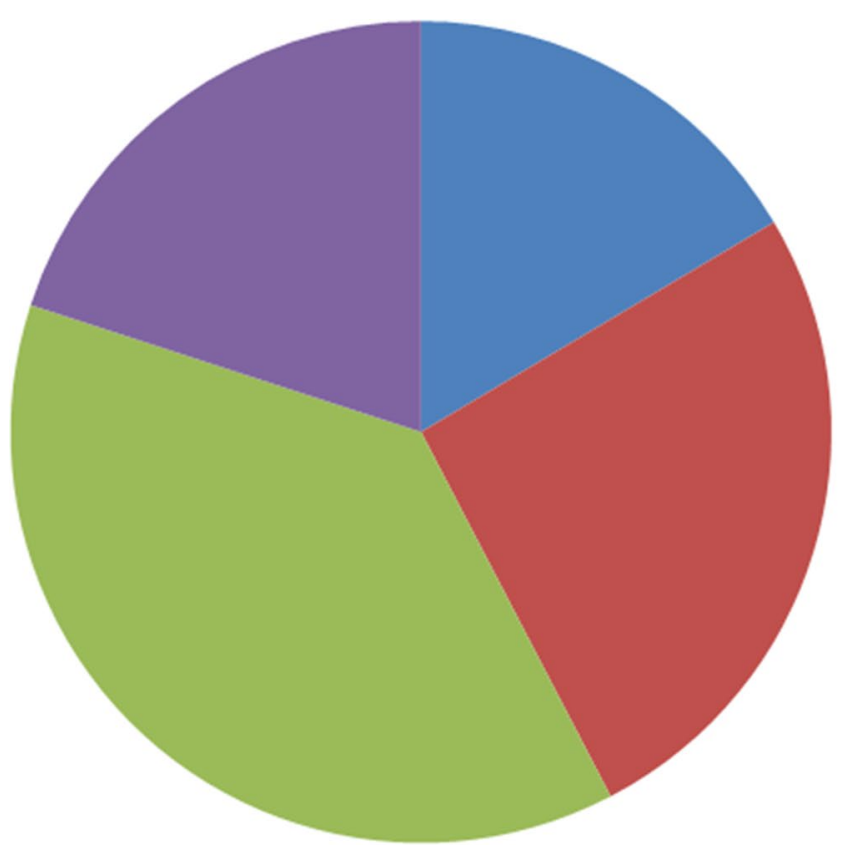

SegUPD

Mosaic SegUPD

Beckwith SegUPD

SegUPD Trip

Fig. 4 Relative incidence of segUPD subgroups seen during study timeframe 
Table 1 Segmental UPD

\begin{tabular}{|c|c|c|c|c|c|}
\hline Case & UPD interval & $\begin{array}{l}\text { TERMINAL } \\
\text { ROH (Mb) }\end{array}$ & Origin & Age/source & Indication \\
\hline 1 & 1 pter $\rightarrow$ p36.22 & 9.39 & Mat & 9.3 years & Multiple congenital anomalies: $\operatorname{der}(1) t(1 ; 17)$ in amnio analysis \\
\hline 2 & 1 pter $\rightarrow$ p36.22 & $9.33^{\mathrm{a}}$ & Mat & CVS and AF & $\begin{array}{l}\text { NIPT: Terminal del(1)(p36), } 60 \% \text { deletion in CVS, copy neutral in AF, normal } \\
\text { fetal ultrasound }\end{array}$ \\
\hline 3 & 1 pter $\rightarrow$ p36.12 & 21.58 & NA & AF & $\begin{array}{l}\text { NIPT: Terminal del(1)(p36), terminal dup(1)(q42); cardiac defect, hypotonic, } \\
\text { dysmorphic at birth }\end{array}$ \\
\hline 4 & 1 pter $\rightarrow$ p36.13 & $16.32^{b}$ & Mat & AF and POC & $\begin{array}{l}\text { NIPT:Terminal del(1)(p36.23) and dup(1)(p36.23p36.22), normal pediatric } \\
\text { follow-up }\end{array}$ \\
\hline 5 & 1 pter $\rightarrow$ p36.13 & $17.28^{c}$ & NA & Newborn and Placenta & $\begin{array}{l}\text { NIPT:Terminal del(1)(p36.13) and mos dup(18)(q22q23), VSD, esophageal } \\
\text { atresia }\end{array}$ \\
\hline 6 & 3 pter $\rightarrow$ p22.1 & $43.13^{d}$ & Mat & 24 years blood and buccal & $\begin{array}{l}\text { Developmental delay, hearing loss, obesity, mosaic unbalanced der(4)t(3;4) } \\
\text { (p22;q35) detected in early childhood }\end{array}$ \\
\hline 7 & 5 pter $\rightarrow$ p15.1 & 16.44 & Mat & 51 years & Cardiomyopathy, hypertension, mental retardation \\
\hline 8 & $7 q 33 \rightarrow$ qter & $26.21^{\mathrm{e}}$ & Mat & CVS and AF & Ventricular septal defect, small right ventricle \\
\hline 9 & $10 \mathrm{q} 26.13 \rightarrow$ qter & 11.12 & Mat & Newborn & Clinically normal; CVS with terminal G-band del(10)(q26) \\
\hline 10 & $11 \mathrm{q} 13.1 \rightarrow$ qter & 70.88 & Mat & 12 years & Encephalopathy \\
\hline 11 & $14 \mathrm{q} 24.3 \rightarrow$ qter & 32.21 & Pat & AF & Scalp and leg edema, short femurs/thorax (UPD14pat related) \\
\hline 12 & 15 q15.3 $\rightarrow$ qter & 58.54 & Pat & 42 years & Recurrent pregnancy loss \\
\hline 13 & Xq25 $\rightarrow$ qter & 29.32 & Mat & Newborn & Fragile $X$ full mutation $\times 2$, no paternal repeat \\
\hline 14 & Xq13.1 $\rightarrow$ qter & 85.05 & Pat & 2 years & Congenital anomalies of face and neck \\
\hline
\end{tabular}

${ }^{a}$ Same ROH in both prenatal specimens; mosaic deletion in CVS, arr 1p36.33p36.22(849466-9292997)x1[0.3]

${ }^{\mathrm{b}}$ Mosaic del/dup in post-delivery POC array analysis, arr 1p36.33p36.23(849466-8718884)x1 [0.8], arr 1p36.23p36.22(8718885-12155862)x3[0.8]

${ }^{c}$ Non-mosaic deletion in POC, arr 1p36.33p36.13(849466-17275759)x1

${ }^{d}$ Mosaic gain in adult blood CMA (chromosome analysis confirmed), arr 3p26.3p22.1(2693-43129322)x3[0.05]

e Mosaic copy neutral ROH in CVS, arr 7q33q36.3(132913480-159119220)x2[0.5] hmz. Non-mosaic in AF

from a balanced inversion carrier, but only maternal (normal) testing was available.

Another patient (case 5) was referred for late gestation NIPT (25 weeks), which showed an increased risk for a non-mosaic terminal $1 \mathrm{p} 36$ deletion and mosaic (37\%) gain of terminal 18q. Post-delivery follow-up revealed the same non-mosaic $1 \mathrm{p} 36$ deletion, but no $18 \mathrm{q}$ duplication in a placental CMA analysis. A blood CMA analysis showed that a copy neutral $\mathrm{ROH}$ had replaced the deleted interval consistent with deletion repair occurring from the proximal end of the deletion.

A G-band chromosome analysis of a 4-year old female with developmental delay revealed mosaicism for an unbalanced translocation, $\operatorname{der}(4) \mathrm{t}(3 ; 4)(\mathrm{p} 22 ; \mathrm{q} 35)$, in $40 \%$ of the metaphases examined (Case 6, Fig. 7A). Twenty years later, the proband was referred for excessive weight gain and a clinical reevaluation. A blood chromosome reanalysis showed the unbalanced derivative in 5\% (6/120) of lymphoid metaphases, while the CMA showed $\sim 8 \%$ partial trisomy (3pter $\rightarrow$ p22.1) with complete homozygosity of the same $43.13 \mathrm{Mb}$ region and no alterations of 4q (Fig. 7B, C). A subsequent buccal microarray showed normal dosage and the same $3 \mathrm{p} \mathrm{ROH}$. A maternal-proband CMA allele comparison and normal maternal blood karyotype was consistent with maternal segmental UPD (segUPDmat) and de novo origin of the unbalanced translocation (Additional file 1: Figure S2). A diagram of the apparent mechanism is shown in Fig. 8.

Peripheral blood from a 29-year old male referred for a developmental disorder was tested using microarray and cytogenetic analyses (Case 35). Chromosome studies revealed mosaicism for two cell lines: ten cells showed a derivative chromosome 21 and the remaining ten cells showed a normal 46, XY karyotype (Fig. 9A). Concurrent microarray studies revealed a $\sim 60 \%$ mosaic $7.12 \mathrm{Mb}$ terminal deletion of chromosome 21 (q22.2 $\rightarrow$ qter) and a $~ 60 \%$ mosaic $30.51 \mathrm{Mb}$ terminal duplication of chromosome 12(pter $\rightarrow$ p11.22) (Fig. 9B, C). The CMA also showed a $24.38 \mathrm{Mb}$ mosaic copy- neutral $\mathrm{ROH}$ in chromosome $21(\mathrm{q} 21.1 \rightarrow \mathrm{q} 22.2)$, proximal to the mosaic deletion (Fig. 9C) with $\sim 40 \%$ homozygosity. The mosaic terminal deletion showed no evidence of heterozygous alleles, consistent with a prezygotic origin, while the proximally adjacent segment showed heterozygous alleles, consistent with a postzygotic origin. The proposed mechanism for this result is mitotic recombination that occurred at 21q21.1 (Fig. 9C, arrow), proximal to the rearrangement breakpoint, resulted in replacement of most of the derivative chromosome 21 with a segment from the normal homologue (Fig. 9D). 
Table 2 Mosaic segmental UPD

\begin{tabular}{|c|c|c|c|c|c|}
\hline Case & segUPD interval & $\begin{array}{l}\text { TERMINAL } \\
\text { ROH (Mb) }\end{array}$ & \% Mosaic HMZ & Age/Source & Indication \\
\hline 15 & 1 pter $\rightarrow$ p22.1 & 93.9 & 50 & 3 years & $\begin{array}{l}\text { Developmental delay, seizures, hearing loss, decreased } \\
\text { motor function }\end{array}$ \\
\hline 16 & 1 pter $\rightarrow$ p36.32 & 2.8 & 34 & 1.9 mos & Seizures in infant, suspect epilepsy \\
\hline 17 & $1 \mathrm{q} 12 \rightarrow \mathrm{qter}$ & 99.4 & 50 & 1.5 years & $\begin{array}{l}\text { Macrocephaly, delays in development and speech, short } \\
\text { stature }\end{array}$ \\
\hline 18 & $1 \mathrm{q} 42.13 \rightarrow$ qter & 20.2 & 15 & CVS & AMA, family history of chromosome abnormality \\
\hline 19 & 3 pter $\rightarrow$ p24.3 & 23.46 & 30 & AF & $\begin{array}{l}\text { AV canal defect, } 2 \text { vessel cord, co-twin with anencephaly, } \\
\text { oligohdramnios }\end{array}$ \\
\hline 20 & 5 pter $\rightarrow$ p13.2 & 36.85 & 50 & CVS & Prenatal anxiety \\
\hline 21 & $9 \mathrm{q} 13 \rightarrow$ qter & 74.2 & 40 & 4 years & Autism \\
\hline 22 & $9 \mathrm{q} 13 \rightarrow$ qter & 74.2 & 20 & POC & Loss at 22 weeks \\
\hline 23 & 11 q13.4 $\rightarrow$ qter & 62.34 & 25 & AF & Clinodactyly, bright bowel \\
\hline 24 & $12 \mathrm{q} 13.13 \rightarrow$ qter & 80.87 & 25 (blood); 15 (buccal); 0 (villi) & NB & $\begin{array}{l}\text { Dysmorphic features, Mowat-Wilson syndrome (a patho- } \\
\text { genic mutation in ZEB2 was correlated with the pheno- } \\
\text { type) }\end{array}$ \\
\hline 25 & $\begin{array}{l}12 \mathrm{q} 13.11 \rightarrow 12 \mathrm{q} 13.13 \\
12 \mathrm{q} 13.13 \rightarrow \text { qter }\end{array}$ & 84.36 & $\begin{array}{l}70 \\
85\end{array}$ & 1.5 years & $\begin{array}{l}\text { Peg teeth, dry skin, developmental delay, speech and motor } \\
\text { delay }\end{array}$ \\
\hline 26 & $13 q 12.3 \rightarrow$ qter & 85.59 & 20 & 5.3 years & Atrial septal defect \\
\hline 27 & $13 q 12.11 \rightarrow$ qter & 94.9 & 35 & 3.9 years & $\begin{array}{l}\text { Essential (primary) hypertension, obesity, abnormal weight } \\
\text { gain }\end{array}$ \\
\hline 28 & $14 \mathrm{q} 12 \rightarrow$ qter & 74.68 & 25 & 8.9 years & Developmental delay \\
\hline 29 & $14 \mathrm{q} 22.1 \rightarrow$ qter & 55.56 & 27 & 3.4 years & Autism, multiple congenital anomalies \\
\hline \multirow[t]{3}{*}{30} & $15 q 13.3 \rightarrow q 15.2$ & & 15 & \multirow[t]{3}{*}{12 years } & \multirow{3}{*}{$\begin{array}{l}\text { Short stature, developmental delay; symptoms consistent } \\
\text { with } 15 q 25.2 \text { microdeletion syndrome }\end{array}$} \\
\hline & $15 q 15.2 \rightarrow q 22.31$ & 71.24 & 46 & & \\
\hline & $15 q 22.31 \rightarrow$ qter & & $75^{\mathrm{a}}$ & & \\
\hline 31 & $15 q 22.31 \rightarrow$ qter & 37.8 & 30 & CVS & NT $3.9 \mathrm{~mm}$ \\
\hline 32 & $16 q 11.2 \rightarrow$ qter & 43.7 & 35 & NB & Microcephaly, fetal growth restriction \\
\hline 33 & $18 \mathrm{q} 11.1 \rightarrow$ qter & 59.5 & 25 & $\mathrm{POC}$ & $\begin{array}{l}\text { Positive MSS, increased risk of } 4 p \text { deletion, features consist- } \\
\text { ent with Wolf-Hirschhorn syndrome }\end{array}$ \\
\hline \multirow[t]{2}{*}{34} & $19 q 13.2 \rightarrow q 13.2$ & 2.75 & 25 & \multirow[t]{2}{*}{35 years } & \multirow[t]{2}{*}{ Progressive progeria-like symptoms, short stature, psychoses } \\
\hline & $19 q 13.2 \rightarrow$ qter & 17.36 & 37 & & \\
\hline 35 & $21 \mathrm{q} 21.1 \rightarrow$ qter & 24.38 & $40^{\mathrm{b}}$ & 29 years & Developmental disorder of scholastic skills \\
\hline 36 & $22 q 11.23 \rightarrow$ qter & 26.6 & 50 & $\mathrm{POC}$ & Abnormal cfDNA screen with fetal demise \\
\hline
\end{tabular}

${ }^{a}$ Mosaic deletion, arr 15q25.1q25.3 (78989949-86981470)x1[0.25]

${ }^{\mathrm{b}}$ Mosaic duplication, arr 12p13.33p11.22(173786-30511741)x3[0.6], and mosaic deletion, arr 21q22.2q22.3(41025556-48097372)x1[0.6]

\section{SegUPD associated with corrections of deletions}

The chorionic villus sample (CVS) analysis in case 9 showed a G-band visible and FISH-confirmed terminal deletion of the long arm of chromosome 10, initiating at band q26.1 in all cells (Fig. 10A). In the absence of ultrasound abnormalities, the parents elected to continue the pregnancy. A post-delivery blood CMA revealed a nonmosaic copy-neutral terminal $\mathrm{ROH}$ of $11.12 \mathrm{Mb}$ on chromosome 10 (q26.13 $\rightarrow$ qter), corresponding to the former deletion interval (Fig. 10B). Parental CMA allelic comparisons were consistent with maternal segUPD (Additional file 1: Figure S3). The newborn appeared clinically normal and, at the age of 3 , there appeared to be no deletion-related symptoms.
An NIPT study consistent with a terminal 1p deletion led to a CVS CMA in case 2. The CMA showed a mosaic deletion/ROH without heterozygous alleles at terminal $1 \mathrm{p}$ and a subsequent amniocyte CMA revealed a copyneutral $\mathrm{ROH}$ in the deletion interval, consistent with a germline error correction and segUPD (Fig. 11). The presence of normal cells $(40 \%)$ in the CVS indicate that correction initiated before fetal development and normal fetal ultrasound results suggested the correction may have preceded clinical effects.

Microarray peripheral blood studies of case 30, a 12-year old female referred for developmental delay and short stature, revealed an $8 \mathrm{Mb}$ mosaic $(\sim 25 \%)$ interstitial deletion of chromosome 15 (q25.1q25.3), along 
Table 3 Segmental UPD contiguous with triplications

\begin{tabular}{|c|c|c|c|c|c|c|}
\hline Case & UPD interval & $\begin{array}{l}\text { Terminal } \\
\text { ROH (Mb) }\end{array}$ & Triplication interval & $\begin{array}{l}\text { Triplication } \\
\text { size (Mb) }\end{array}$ & Age/source & Indication \\
\hline 37 & 1 pter $\rightarrow$ p36.22 & 11.62 & $1 p 36.22 \rightarrow p 36.21$ & 1.32 & 4.8 years & None given \\
\hline 38 & 1 pter $\rightarrow$ p36.13 & 19.35 & 1 p36.13 $\rightarrow$ p36.12 & 3.56 & 7.6 years & None given \\
\hline 39 & 1 pter $\rightarrow$ p36.33 & 1.49 & $1 p 36.33 \rightarrow$ p36.32 & 2.09 & 1.2 years & Developmental delay \\
\hline 40 & $1 \mathrm{q} 43 \rightarrow$ qter & 10.07 & $1 \mathrm{q} 42.3 \rightarrow \mathrm{q} 43$ & 4.23 & NB & Multiple congenital anomalies \\
\hline 41 & 2 pter $\rightarrow$ p24.2 & 17.48 & $2 \mathrm{p} 24.2 \rightarrow \mathrm{p} 23.3$ & 8.24 & CVS & Cystic hygroma \\
\hline 42 & 3 pter $\rightarrow$ p25.1 & 13.65 & $3 p 25.1 \rightarrow p 24.1$ & 14.7 & 4.9 years & Developmental delay \\
\hline 43 & 4 pter $\rightarrow$ p 15.2 & 26.02 & $4 p 15.2 \rightarrow p 14$ & 13.37 & NB & None given \\
\hline 44 & $4 \mathrm{q} 31.21 \longrightarrow$ qter & 35.3 & $4 q 31.21->q 32.1$ & 11.49 & 34.8 years & Unspecified intellectual disabilities \\
\hline 45 & 5 q31.3 $\rightarrow$ qter & 40.83 & $5 q 31.2 \rightarrow q 31.3$ & 0.906 & 1.5 years & None given \\
\hline 46 & $8 p t e r \rightarrow p 12$ & $31.31^{\mathrm{a}}$ & $8 p 12 \rightarrow p 11.21$ & 11.03 & POC & Cystic hygroma \\
\hline 47 & $8 p t e r \rightarrow$ p21.1 & 24.38 & $8 p 21.2 \rightarrow p 12$ & 5.2 & 25 years & Brain deformity, developmental delay, hearing loss \\
\hline 48 & $8 q 24.3 \rightarrow$ qter & 0.19 & $8 q 24.13->q 24.3$ & 23.31 & AF & Thickened NT, suspected heart defect, cleft palate \\
\hline 49 & $9 \mathrm{pter} \rightarrow \mathrm{p} 22.3$ & 15.47 & $9 p 22.3 \rightarrow p 21.3$ & 9.66 & 5.9 years & Developmental delay \\
\hline 50 & 17 pter $\rightarrow$ p13.3 & 1.91 & $17 p 13.3 \rightarrow p 13.2$ & 3.78 & 13 years & Developmental delay \\
\hline 51 & $17 q 25.3 \rightarrow$ qter & 2.23 & $17 q 25.3 \rightarrow 25.3$ & 3.07 & 2.6 years & Delayed milestones \\
\hline 52 & $\begin{array}{l}21 \text { q21.1 } \rightarrow \text { qter } \\
\quad(70 \%, 30 \% \text { del })\end{array}$ & 28.1 & $21 \mathrm{q} 11.2 \rightarrow$ q21.1 (3.4 copy) & 5 & POC & Advanced maternal age \\
\hline 53 & 22 q13.31 $\rightarrow$ qter & 3.57 & $22 q 13.2 \rightarrow q 13.31$ & 5.23 & 1.1 years & Microcephaly \\
\hline
\end{tabular}

${ }^{a}$ Mosaic deletion/duplication-triplication:arr 8p23.3p23.1(158048-31307174)x1 [0.2], 8p23.1(31307174-42334760)x4[0.7]

A

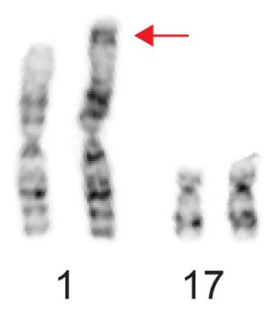

B

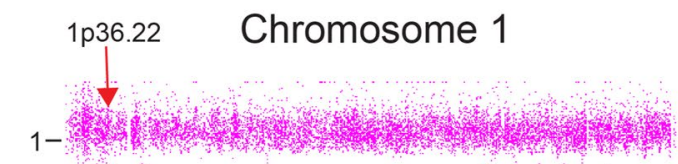

Allele

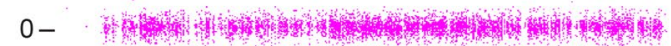

peaks

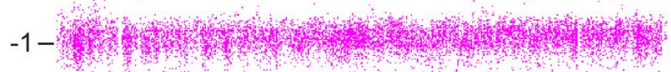

$3-$

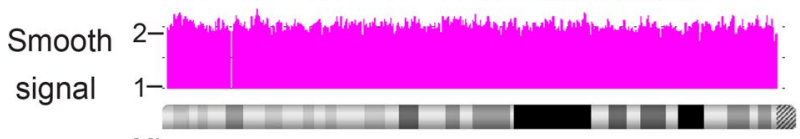

$\mathrm{Mb}$
C Chromosome 17

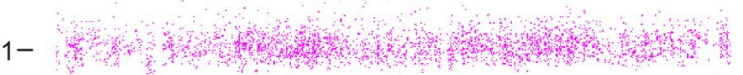

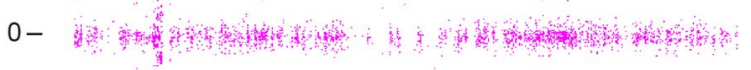

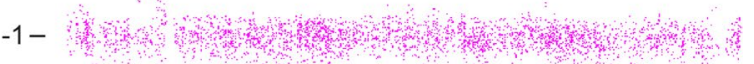

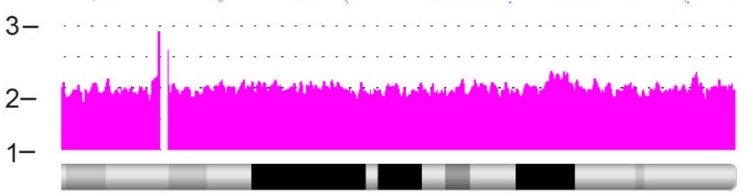

$\mathrm{Mb}$

Fig. 5 Correction of der(1)t(1;17) in case 1. A Partial karyotype of the 16 week amniocyte analysis in case 1. FISH and parental studies confirmed a de novo unbalanced derivative $(1) t(1 ; 17)(p 36.3 ; q 21)$ (arrow). B, C Blood array analysis at age 9 showed a terminal $9.4 \mathrm{Mb}$ copy neutral ROH on chromosome 1 initiating at band p36.22 (arrow) with no deletion of $1 p$ or evidence of partial trisomy 17 


\section{Chromosome 1}
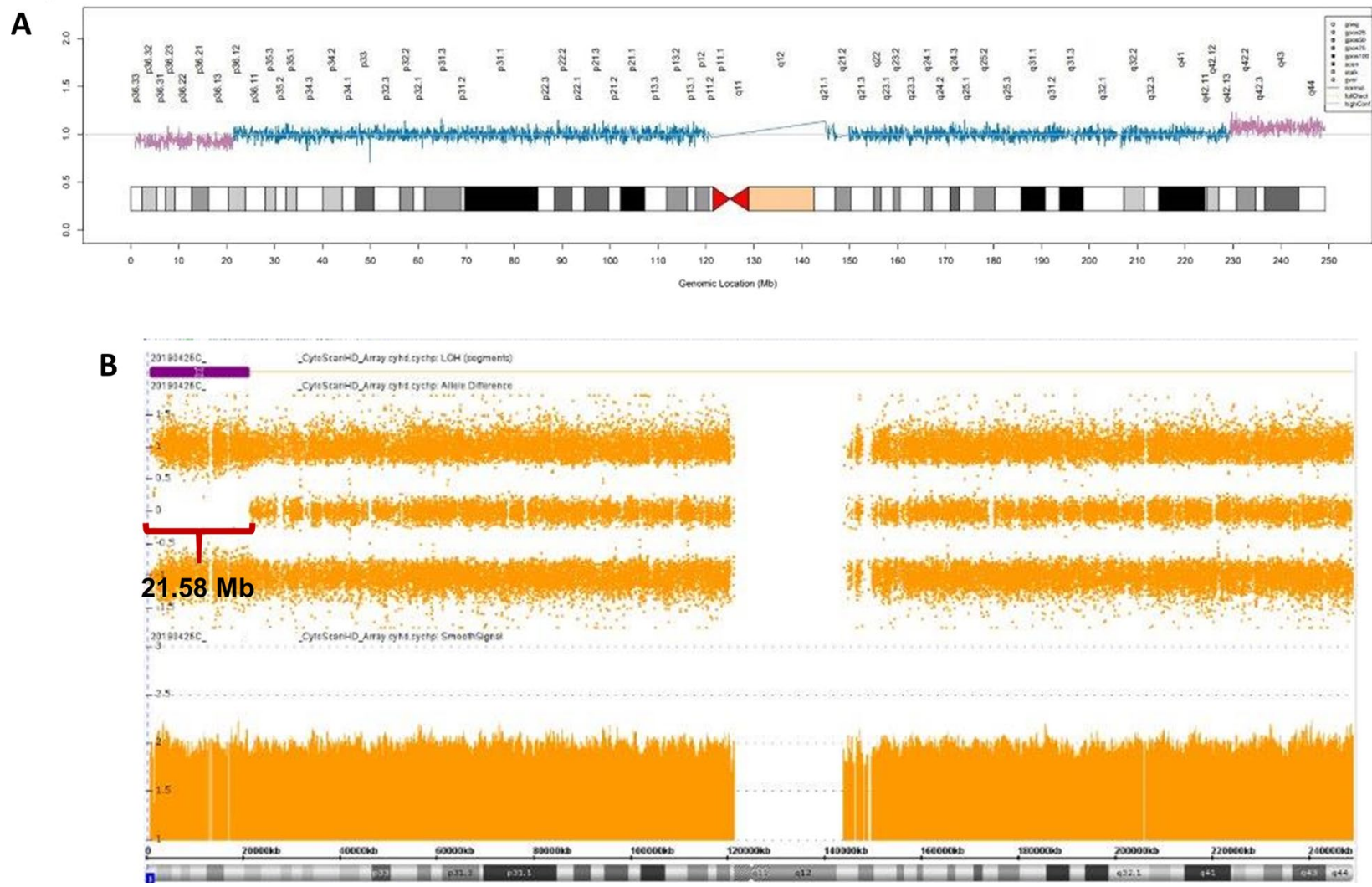

Fig. 6 Possible inversion recombinant correction in case 3. A NIPT study, referred due to a cardiac lesion, showing a terminal deletion of $1 p$ and a duplication of terminal 1q (A), with both equivalent to the 13\% fetal fraction, consistent with non-mosaic fetal alterations. B Subsequent microarray analysis at 23 weeks of gestation showed no dosage changes of chromosome 1, although a $21.58 \mathrm{Mb}$ terminal 1p ROH was present (B)

with three different percentages of mosaic homozygosity associated with three proximal recombination sites (Fig. 12). The most proximal region extended from $15 \mathrm{q} 13.3 \rightarrow \mathrm{q} 15.2$, with an allele difference tract consistent with $15 \%$ homozygosity. The next region extended from $15 \mathrm{q} 15.2 \rightarrow \mathrm{q} 22.31$, with the tract consistent with $\sim 46 \%$ homozygosity, and the most distal region extended from $15 \mathrm{q} 22.31$ to the terminus of chromosome 15 with 70\% homozygosity.

\section{SegUPD with a possible postzygotic origin of allelic imbalance}

Three cases suggest a somatic origin of allelic imbalance, resulting in apparent segUPD. In case 8 , the original CVS CMA showed 50\% copy-neutral homozygosity at terminal $7 \mathrm{q}$ and the subsequent amniotic fluid CMA was $100 \%$ homozygous in the same region. The placental absence of a dosage deficit in the presence of a terminal mosaic $\mathrm{ROH}$ on chromosome 7 is not consistent with deletion rescue; the further homozygous evolution in the amniocyte analysis is suggestive of active selection for the gene converted segment.

The results of 3 CMAs of a newborn male from case 24 showed a normal placental analysis, but mosaicism for a 12q terminal ROH and apparent segUPD in both blood and buccal cell CMAs (Fig. 13). The patient phenotype could not be specifically linked to either partial monosomy or to a mutation in the segUPD interval. An unrelated pathogenic mutation subsequently detected in the ZEB2 gene (2q22.3) was consistent with the patient symptoms (Mowat-Wilson syndrome, OMIM\# 235730).

Case 34, a 35-year old male, showed progeria-like symptoms that progressed with age. The CMA from peripheral lymphocytes demonstrated two apparent segUPD subpopulations with separate mitotic recombination initiation sites on the long arm of chromosome 19. 

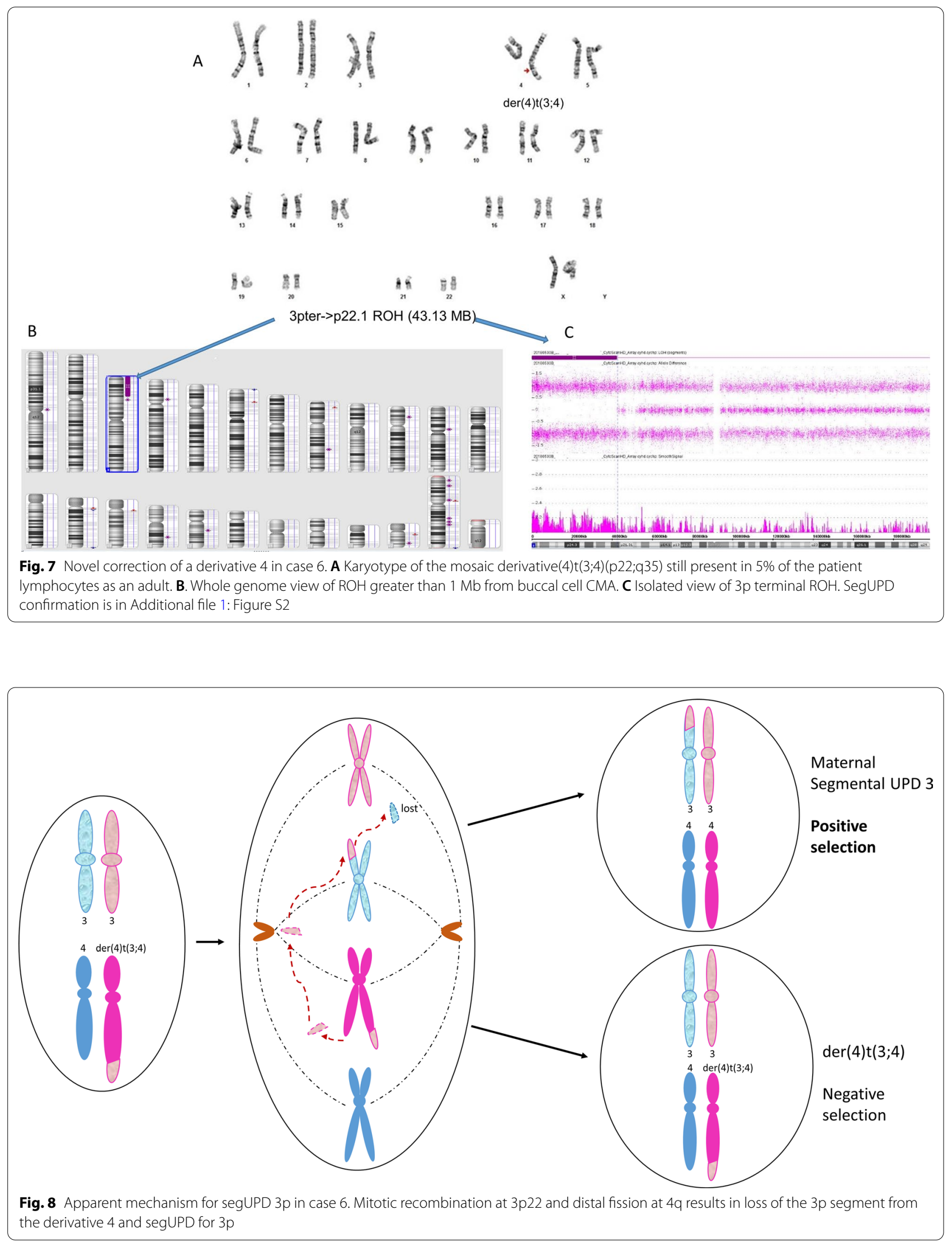


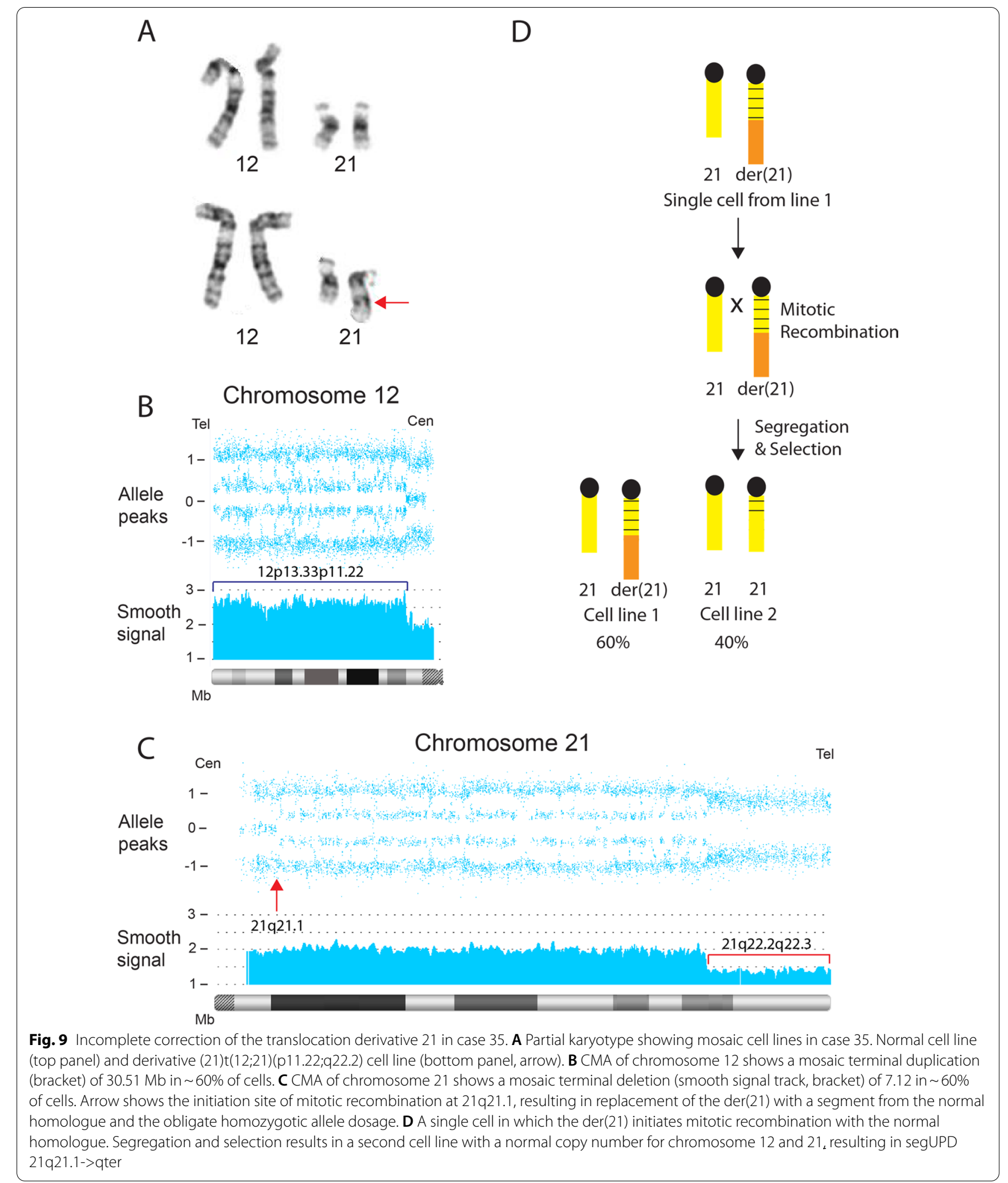

\section{SegUPD associated with contiguous duplication} and terminal deletion

DNA isolated from routine placental-based NIPT screening studies from a 16-week female fetus showed an increased risk for an $\sim 8 \mathrm{Mb}$ terminal deletion of $1 \mathrm{p}$ with a contiguous proximal duplication (case 4, Fig. 14A). 


\section{A}

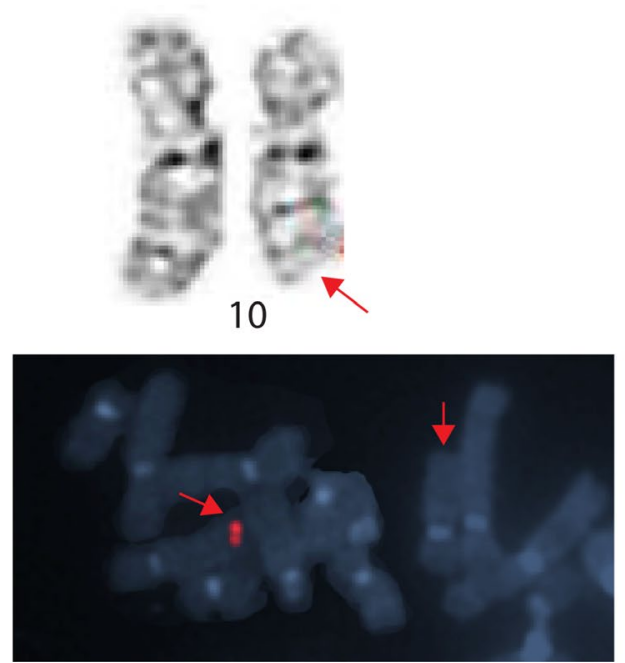

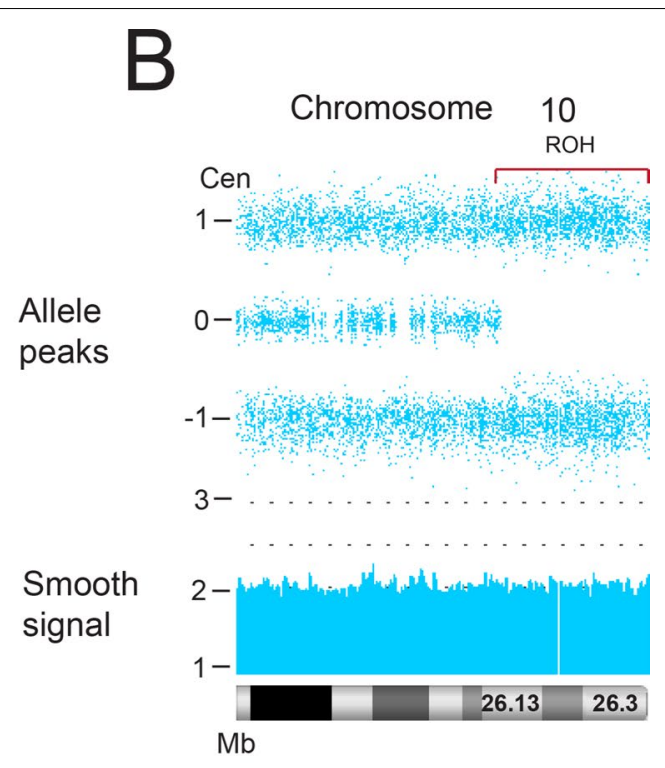

Fig. 10 Analysis of prenatal deletion in case 9. A Case 9 showing a deletion of 10q present in all cells from a CVS chromosome analysis (top panel, arrow) that was confirmed by a region-specific FISH probe (bottom panel, arrow). B Post-delivery blood CMA revealing a copy neutral terminal ROH on chromosome 10 initiating at band q26.13 (bracket). Confirmation of segUPD is shown in Additional file 1: Figure S3

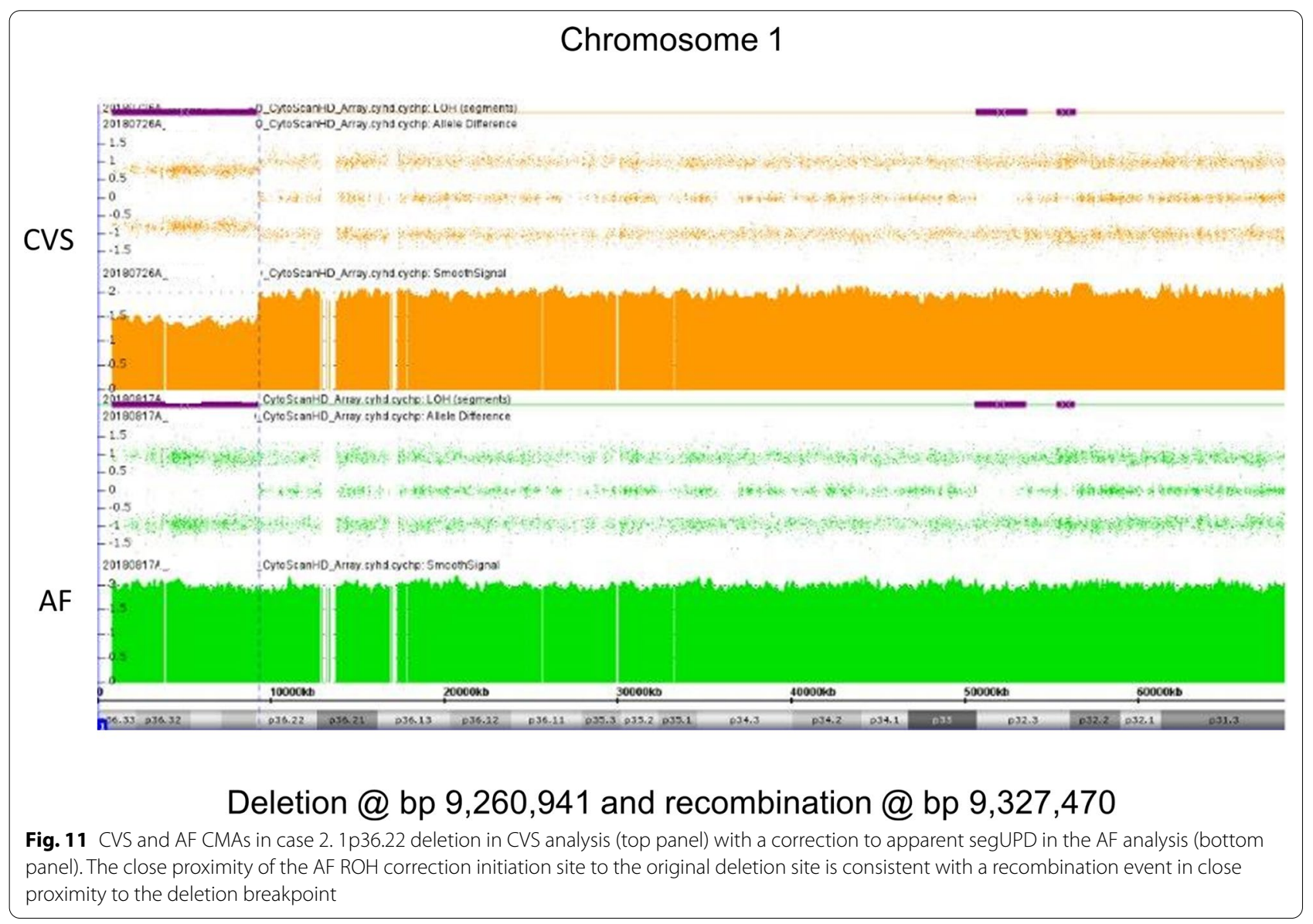




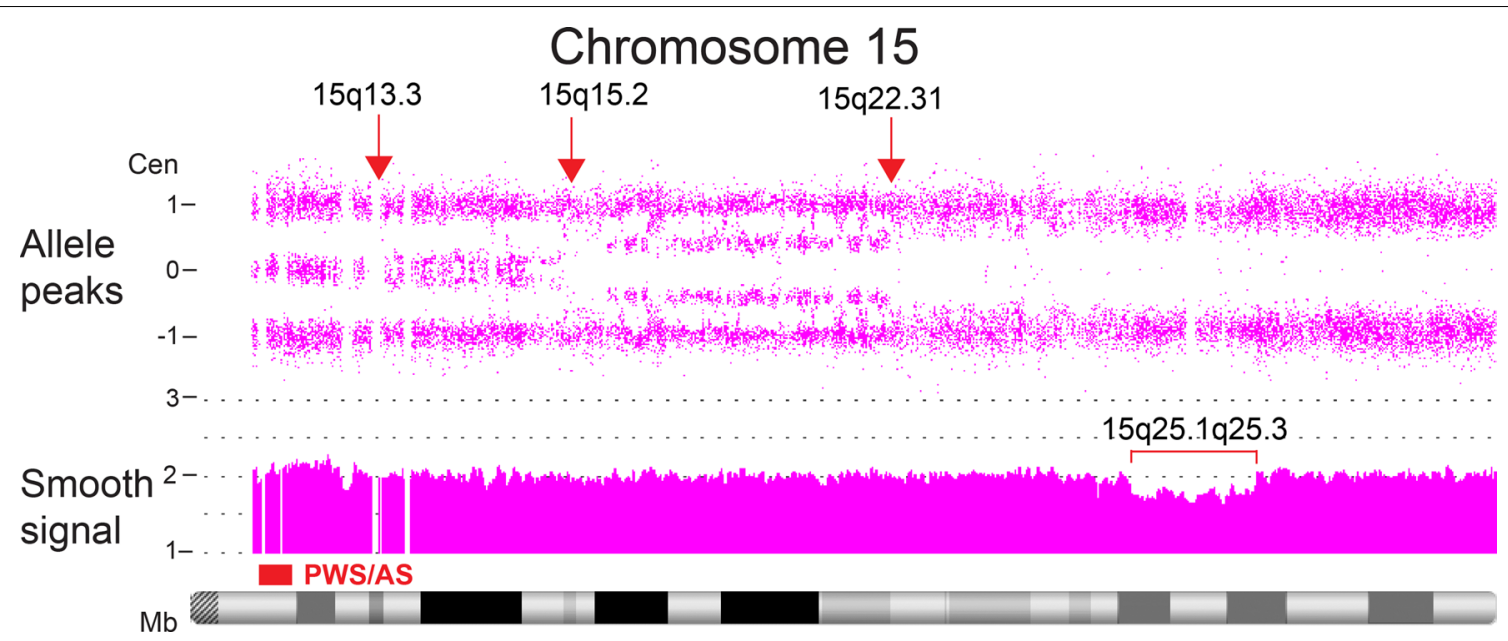

Fig. 12 Mosaic segUPD15 associated with 3 distinct corrections of an interstitial deletion detected in case 30. Three deletion repair cell lines initiate at different mitotic recombination sites (arrows). The deletion (bracket) is still present in $\sim 25 \%$ of cells. Note that the allele difference tract shows $\sim 75 \%$ of cells with homozygosity in the location of the deletion, consistent with the percentage of deletion correction

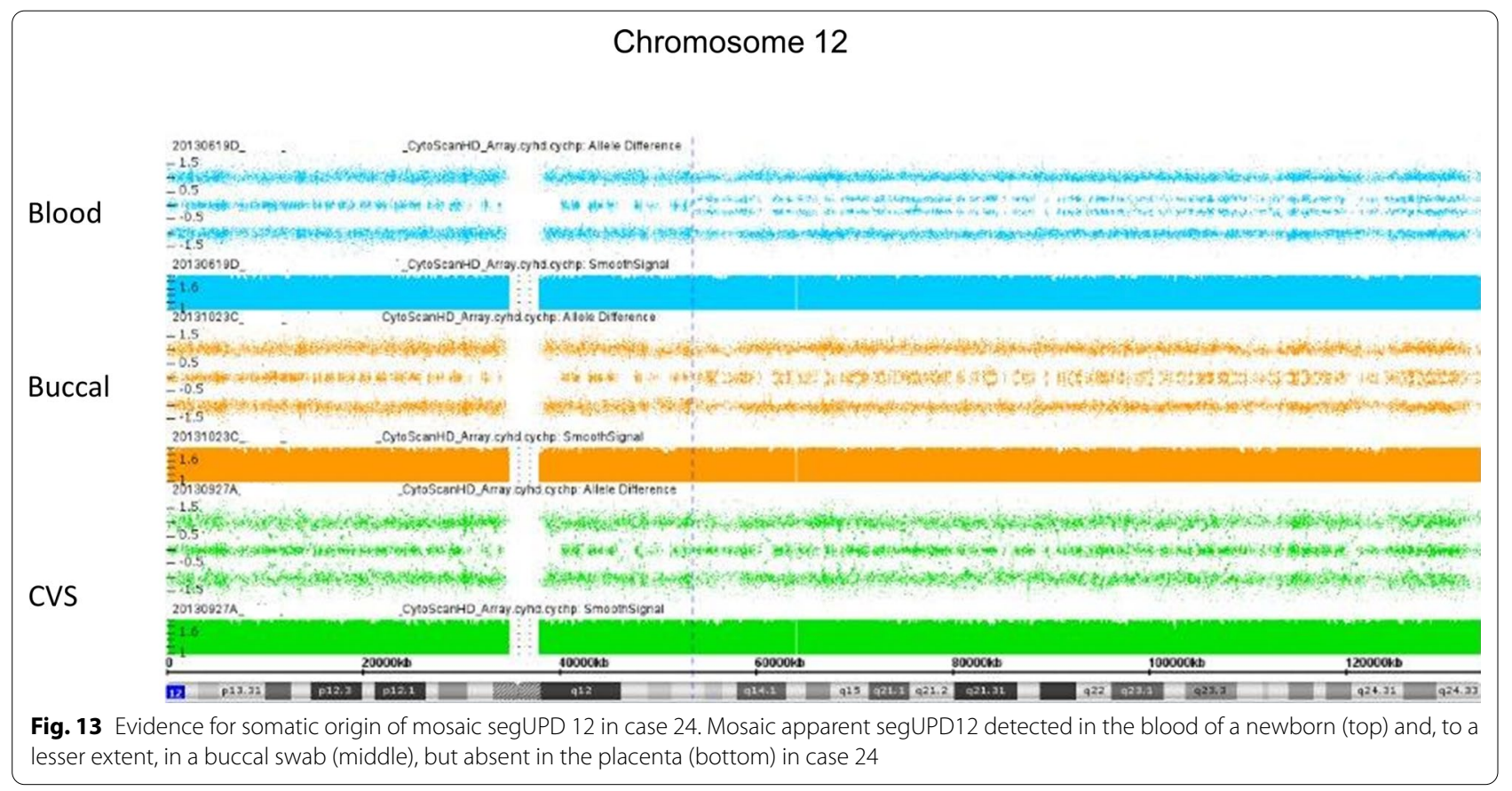

A subsequent amniocyte microarray analysis revealed a normal female dosage with a terminal $16.32 \mathrm{Mb} \mathrm{ROH}$ on the short arm of chromosome 1 that extended proximally to 1 p36.13 (Fig. 14B). This ROH was shown to be segUPD of maternal origin by parental microsatellite analysis. At delivery, only normal G-banded metaphases from lymphocytes were detected in 50 cells analyzed. A microarray from pooled placental biopsies post-delivery showed equivalent $80 \%$ mosaicism for an $8.72 \mathrm{Mb}$ terminal deletion and a contiguous $3.44 \mathrm{Mb}$ duplication extending from $1 \mathrm{p} 36.23$ to $1 \mathrm{p} 36.22$, in agreement with NIPT studies. The $\mathrm{ROH}$, thus, originated $4.14 \mathrm{Mb}$ proximal to the duplication, consistent with homologous recombinationmediated repair occurring at a location distant from the rearrangement.

\section{SegUPD associated with a contiguous triplication}

Terminal segUPD with a contiguous triplicated interval was found in 17 cases (Table 3) and is exemplified by case 38, a 7.6-year old male. The blood leukocyte CMA 


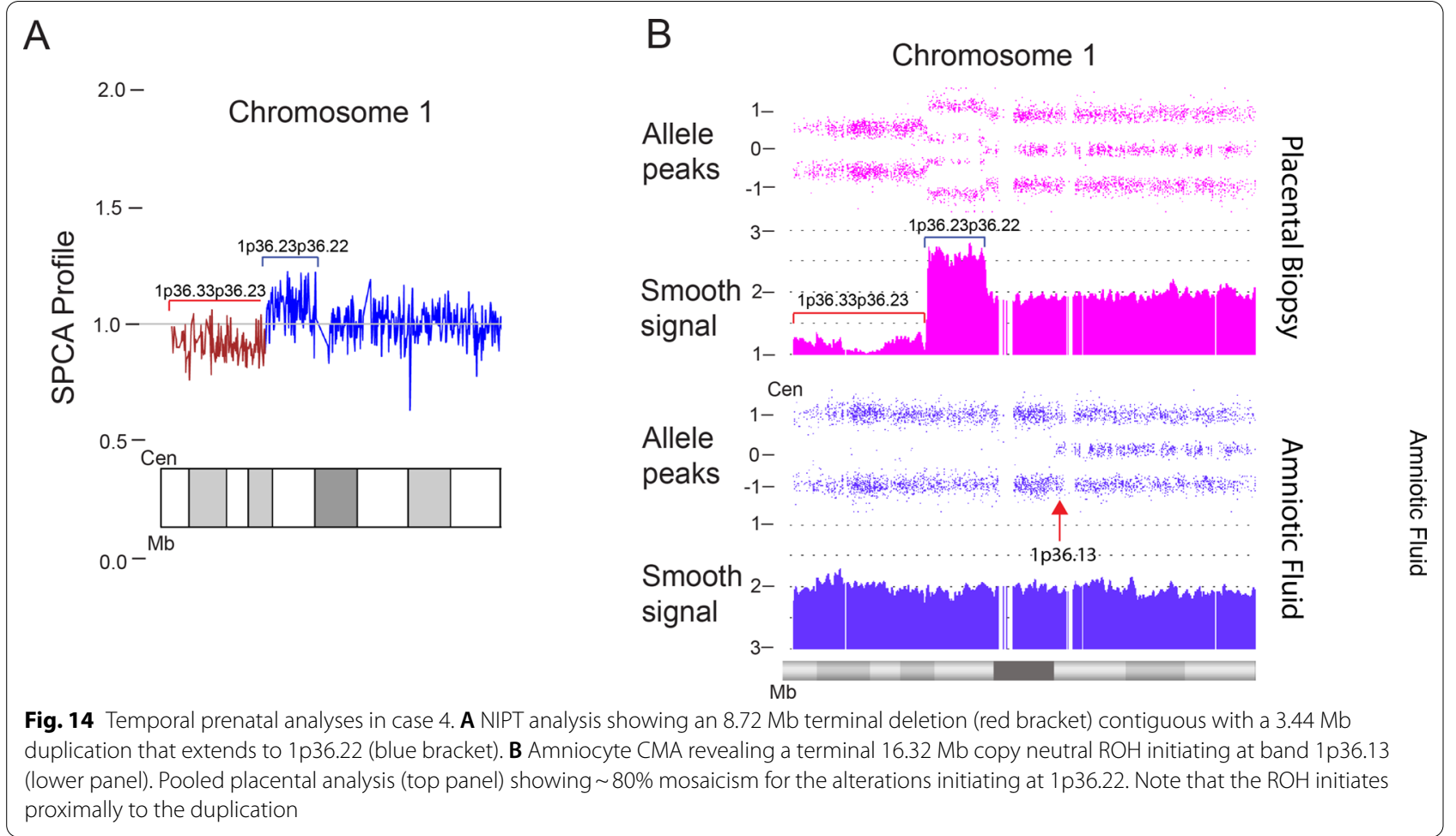

showed a $19.35 \mathrm{Mb}$ terminal 1p ROH with a proximal contiguous $3.56 \mathrm{Mb}$ triplication extending from $1 \mathrm{p} 36.13$ to 1 p36.12 (Fig. 15A). A defining feature of cases in this group is an exclusive 2:2 heterozygous allele dosage
$(\mathrm{AABB})$ in the triplicated segment with no 3:1 relative allele dosage [20] (Fig. 3) and a tandem triplication structure in a single homologue with an inverted middle copy, as confirmed by interphase FISH (Fig. 15B). A

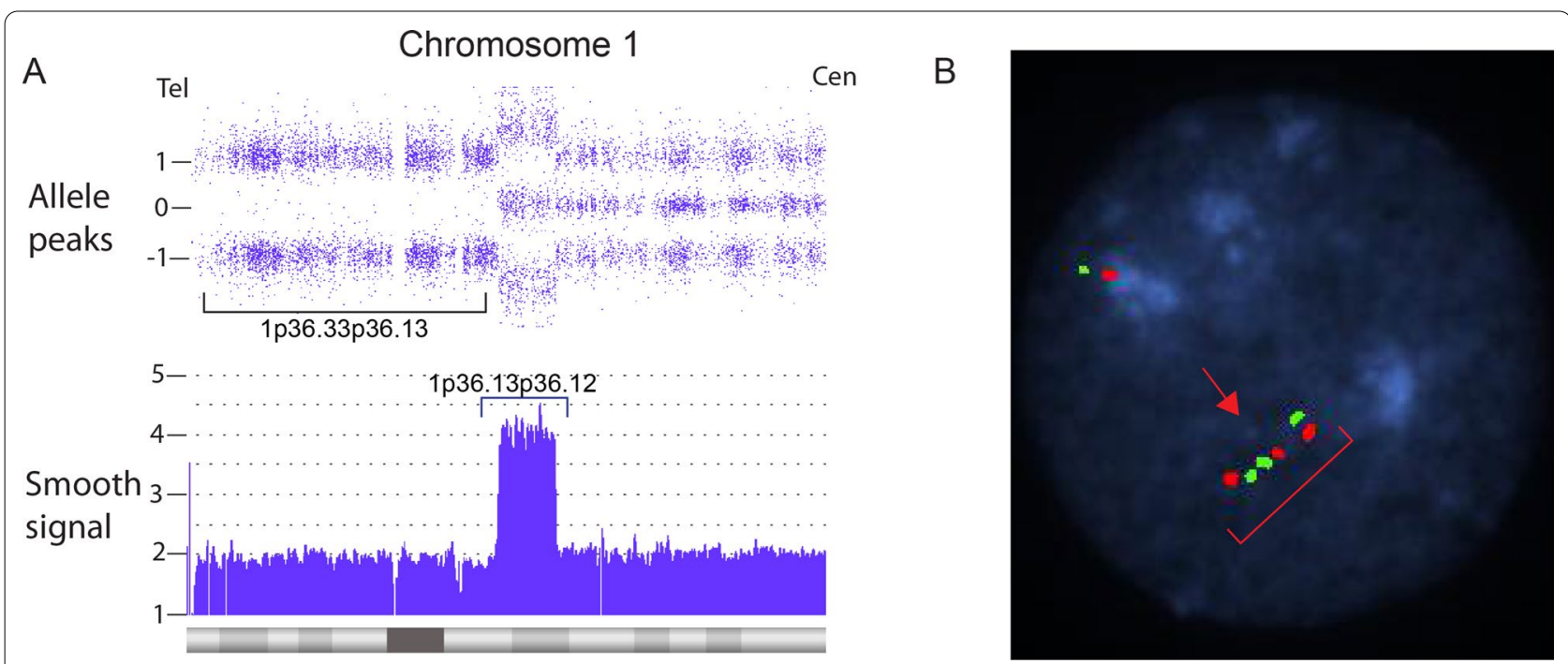

Fig. 15 CMA and FISH analyses of a case of segUPD associated with a triplication. A Microarray image of case 38, shows 3.56 Mb triplication (blue bracket) of bands p36.13p36.12 on chromosome 1 with an exclusive 2:2 (AABB) heterozygote allele pattern and a contiguous copy neutral terminal $19.35 \mathrm{Mb} \mathrm{ROH}$ (bracket). B A dual target interphase FISH image showing triplication of $1 \mathrm{p}$ (bracket) with inverted orientation of the middle segment (arrow) 
mechanistic ideogram of this class of rearrangement is presented in Fig. 16, which shows replacement of a terminal deletion and adjacent proximal inverted duplication with a terminal region of segUPD and adjacent triplication by somatic telomere capture from the normal homologue.

A CMA from placental analysis of a fetal loss provides an example of an apparent incomplete correction of an 8p alteration in this subgroup (case 46, Fig. 17). A $31.31 \mathrm{Mb}$ terminal short arm $\mathrm{ROH}$ showed a $20 \%$ dosage deficit. Contiguous with the deletion was an $11 \mathrm{Mb}$ copy gain extending from band p12 to p11.21, which displayed the characteristic equal 2:2 dosage of heterozygous alleles in this subgroup with copy number of approximately 3.7. The dosages are commensurate with an $\sim 80 \%$ somatic correction of the original deletion and gain of an extra copy of the duplicated region.

\section{Studies of gonadal mosaicism}

Two maternal CMAs (Fig. 18) were pursued to determine the etiology of apparent gonadal mosaicism following repeat alterations, a terminal deletion contiguous duplication of $4 p$ and deletion of $6 q$, in two pregnancies of clinically normal mothers. In both cases, a previous child was born with identical alterations (terminal deletion/proximal duplication of $4 \mathrm{p}$ and terminal deletion of $6 q$, respectively). In both families, the children were severely affected, while the phenotypically normal mothers showed mosaicism for the alterations in buccal cells ( $25 \%$ and $11 \%$, respectively). The mother of the $6 \mathrm{q}$ - children also showed the deletion in blood cells (35\%). These alterations were apparently somatically-derived and not associated with segUPD. However, they are included to show that allele dosage patterns in CMAs can differentiate corrections of somatically-derived alterations, in which heterozygous alleles are present in the deletion interval, from meiotic alterations, which are devoid of heterozygous alleles and associated with segUPD. Heterozygous alleles can be present in mosaic deleted intervals only when the normal cells demonstrate biparental inheritance in the deletion interval and, thus, heterozygosity indicates that the deletion arose post-zygotically. Conversely, the template copy generated from the undeleted homologue in mitotic recombination-based correction of meiotic errors has no heterozygote alleles (also see Fig. 9 C from patient 35 above).

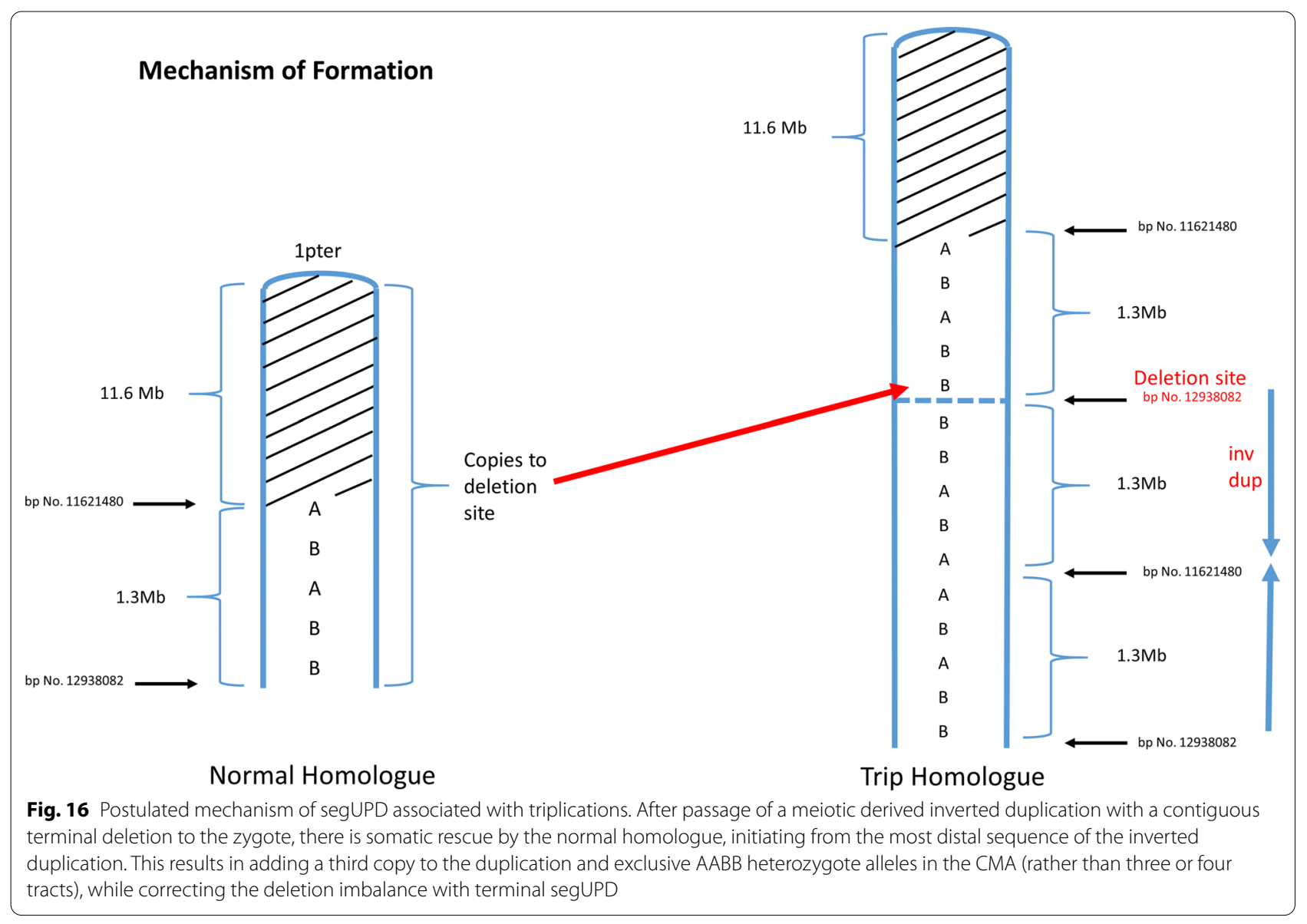




\section{Chromosome 8}
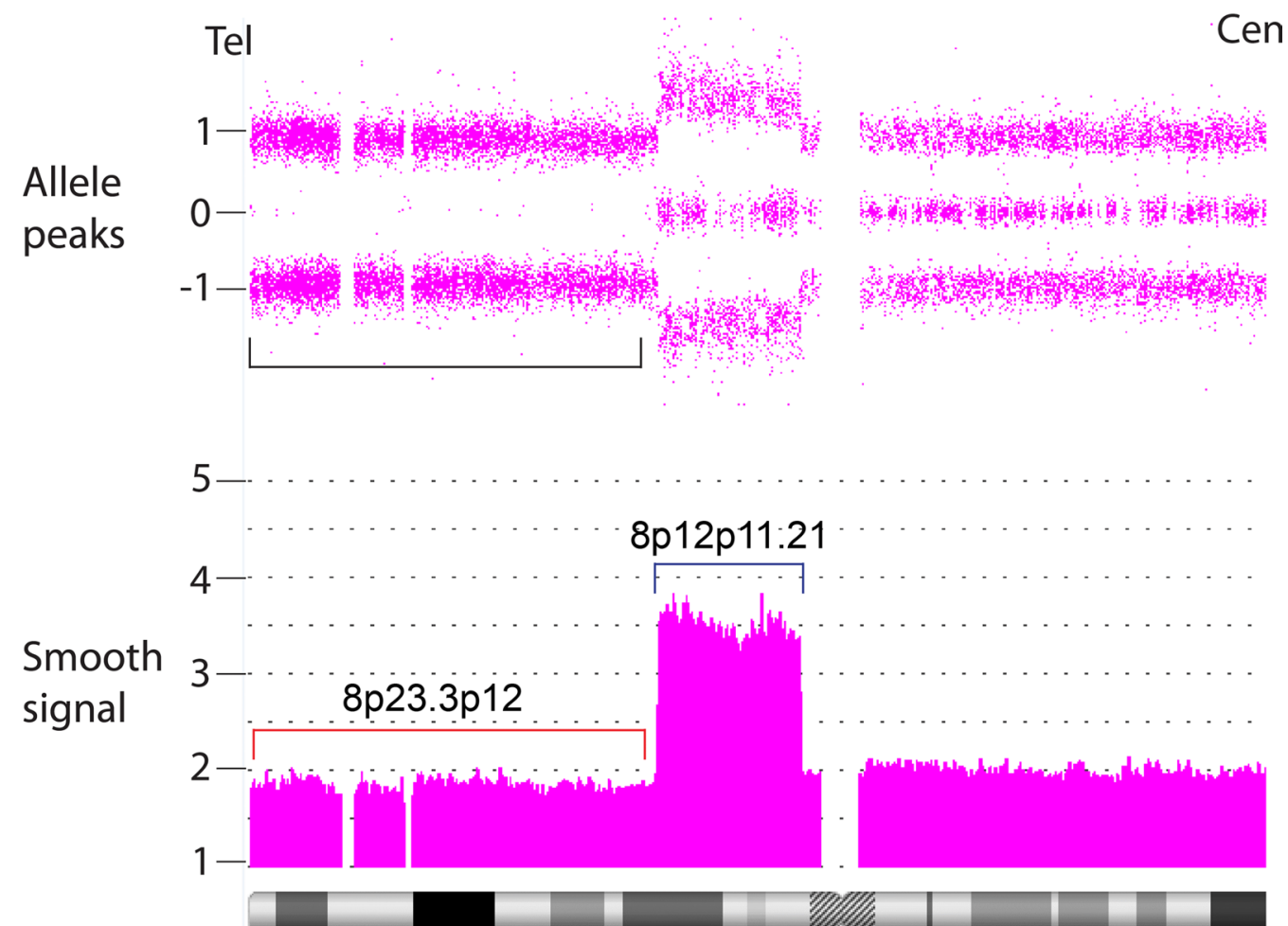

Fig. 17 Mosaic example of a segUPD/triplication correction. The fetal demise from patient 46 showed terminal homozygotic alleles and smooth signal dosage consistent with $~ 80 \%$ replacement of a terminal $8 p$ deletion/proximal duplication with a copy of the terminal segment from the normal homologue, resulting in terminal segUPD visualized by a terminal ROH (bracket) and a contiguous triplication with the characteristic exclusive balanced AABB heterozygote alleles (smooth signal track, blue bracket). Replacement of the deletion with material from the normal homologue appears to have initiated at the distal end of the contiguous duplication

A possible case of gonadal mosaicism due to incomplete mitotic correction of a meiotic imbalance is provided by case 12, a blood CMA from a 42-year old, apparently clinically normal female with a history of 5 fetal losses. The array showed a long terminal $\mathrm{ROH}$ on chromosome 15q, suggestive of UPD15. Since the ROH was distal to the Prader-Willi/Angelman Syndrome region and the patient did not have either imprinting syndrome, whole chromosome UPD was unlikely. Paternal segUPD15 was confirmed (Additional file 1: Figure S4). Because oocytes are produced early in embryogenesis with no mitotic opportunity to correct, the patient's infertility may be associated with a high proportion of oocytes carrying a deletion or some other aberration.

\section{Discussion}

\section{General mechanism: SegUPD and selection}

Most of the patient studies in this report demonstrate segUPD that correlates with mitotic recombinationbased somatic correction of apparent meiotic imbalance involving terminal chromosome arms. Mosaic seqUPD may also arise from a normal zygote related to an expansion of a clonal population of cells derived from a single progenitor cell. These cells show no copy number alteration, but demonstrate selection driven by homozygosity of a gene in one of the homologues providing proliferative advantage, as is the case in Beckwith-Wiedemann syndrome. Both mechanisms appear to require that stochastic double-stranded breaks occur, followed by interhomologue sister chromatid exchanges initiating this process [21], after which there is segregation of somatic recombinants and subsequent proliferation of those recombinants with a selective advantage (Fig. 2).

Patent evidence of a meiotically-derived terminal deletion is depicted in case 9, which shows a 10q terminal deletion in all cells of a CVS chromosome analysis and complete correction in a subsequent newborn blood CMA. Evidence of frequent placentally-confined aneusomy supports the assertion that selection against a genomically unbalanced cell line is much greater in the 


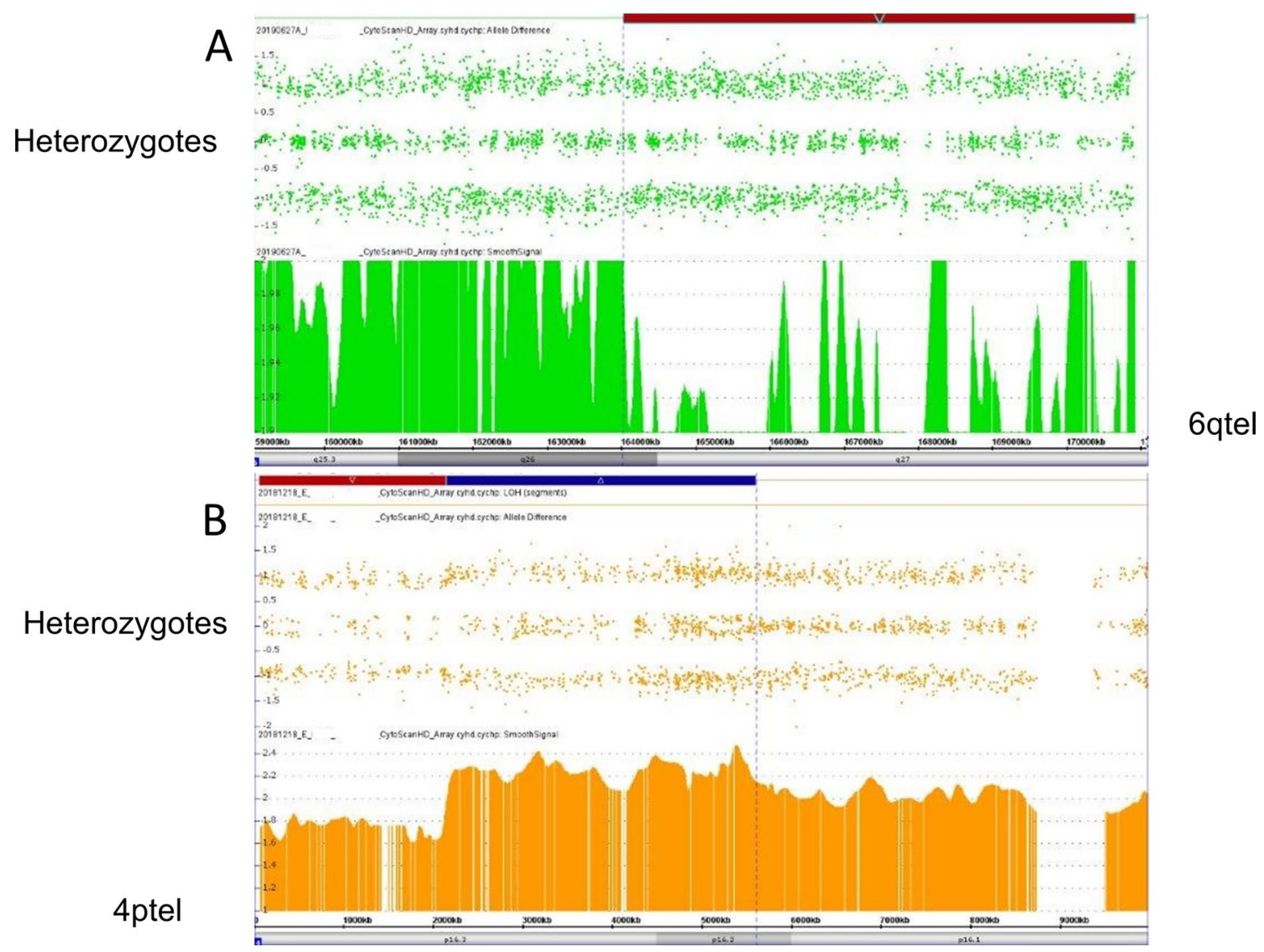

Fig. 18 Study showing post zygotic origin of gonadal mosaicism. A Maternal buccal CMA follow-up from the mother of two 6q- offspring revealing a mosaic 11\% deletion, red bar. B Maternal buccal follow-up from the mother of two offspring with a 4p deletion-duplication showing 25\% deletion (red bar) and duplication (blue bar). Note that the presence of heterozygote alleles in the allele difference tract in the deletion interval are consistent with a post zygotic origin of the gonadal mosaicism and inconsistent with segUPD related correction

fetus than in the placenta $[2,22]$. The placental-fetal stage at which the imbalance completely corrects is likely to be critical in regard to potential developmental effects.

Four NIPT studies that preceded CMAs, each involving terminal deletions of $1 \mathrm{p}$, offer etiological insight.

The proximal loci of the original deletion breakpoint and the subsequent $\mathrm{ROH}$ appear to be the same in cases 2 and 3, consistent with the breaksite being the initiation site of mitotic recombination. The presence of normal cells in the CVS detected from case 2 suggests that correction initiated before fetal development, resulting in no fetal monitoring anomalies detected. In contrast, in case 3 neither the imbalance detected by NIPT nor the corrected amniocyte microarray showed evidence of mosaicism, so the timing of correction in the pregnancy and potential clinical effects are unclear. However, the fetal heart defect, which has been noted in some cases of distal $1 p$ deletions, suggests that the correction occurred too late to prevent pathogenicity.
The NIPT correlative case 4 revealed correction of another common type of germ line alteration, terminal deletion/contiguous duplication. The early gestational NIPT dosage was consistent with this alteration at the $1 \mathrm{p}$ terminus, (confirmed by a post-delivery placental biopsy CMA), and the subsequent amniotic fluid CMA showed complete dosage correction. In contrast to cases 2 and 3 , mitotic recombination initiated proximally to the rearrangement by breaksites established from the placental biopsy, which showed mosaicism for the rearrangements and, thus, was in the process of correction. Since dosage can be normalized by recombination at any point proximal to the imbalance, including the most proximal point of the imbalance, there would appear to be no specific selective advantage associated with the ultimate recombination site. Indeed, the random nature of proximal arm recombination initiation sites and the relative lack of interstitial sites in gene conversions has been noted in previous research [23-25]. 
The fourth NIPT case had a non-mosaic terminal 1p36 deletion and mosaic terminal 18q gain that was corrected in blood, but not in the placenta, consistent with two different somatic mechanisms. The absence of the 18q gain in the blood CMA strongly suggests that it was acquired in a population of placental cells because of the need for a 1p telomere via telomere capture [26]. However, there was subsequent selection for a euploid cell line with segUPD-related correction, rather than the telomere capture cell line with the deletion and partial trisomy. Neonatal symptoms of the $1 \mathrm{p} 36$ deletion syndrome indicate the correction was too late to prevent clinical effects.

The blood and buccal CMA analyses in case 1 show complete correction of a single derivative 1 of a $t(1 ; 17)$ (p36;q21), identified 9 years prior in amniocyte metaphases (Fig. 5). Unlike cases 4 and 9, the clinical effects in this child were clearly due to fetal involvement of the imbalance, since the der(1) was detected in $96 \%$ of the amniocytes. Fetal involvement of the aberrant cell line is unclear in cases 4 and 9, in which abnormalities were ascertained because of NIPT and CVS chromosome studies, respectively. This illustrates the difficulty in predicting clinical effects associated with a transient genomic imbalance due to the timing of correction in some prenatal studies.

Case 35 illustrates apparent incomplete correction of a translocation derivative chromosome [der(21)t(12;21)], which showed mosaicism for the aneuploid and diploid cell lines in G-banded lymphocytes. This illustrates the potential for a mosaic unbalanced translocation derivative to have been inherited, with the normal cells acquired somatically.

Case 6, the correction of a de novo $\operatorname{der}(4) \mathrm{t}(3 ; 4)$ (p22;q35)mat through apparent mitotic recombination with the paternal chromosome 3 homologue, is unique for a number of reasons. This was the only correction found that was mediated by a break in a chromosome other than in the original derivative. It was also the only case with a correction associated with a partial gain and no apparent loss. The complete correction in the buccal CMA and incomplete correction in the blood CMA would appear to be atypical, assuming that more rapidly dividing cells will selectively correct faster than slower dividing counterparts [27]. However, tissue specific selection presumably varies during differentiation, which can alter relative cell line involvement as found in PallisterKillian syndrome [28].

Two cases with apparent maternal gonadal mosaicism displayed post-zygotically derived imbalances of $4 p$ and $6 \mathrm{q}$ that were detected in blood and buccal cells. It may seem unlikely that an abnormal cell population with a post-zygotic origin would be sustained through development when competing with a normal cell population, but evidence of this occurring is provided by these familial studies. The reproductive recurrences of the $4 p$ and 6q lesions were consistent with gonadal mosaicism due to an early developmental error that included the germ cells. Interestingly, the 6q- cells were found in maternal lymphocytes, while the $4 \mathrm{p}$ imbalance was normal in a blood CMA and mosaic in a buccal CMA. Again, this may relate to differences that can exist in tissue-specific selection.

A reproductive recurrence risk in a clinically normal individual who underwent genomic correction of a meiotic derived imbalance in early development is also possible, as revealed by case 12 (with a history of five fetal losses and paternal segUPD15). The patient's infertility could be associated with a high proportion of oocytes carrying a deletion or some other aberration that failed to be corrected in those cells because of the timing of oocyte production in embryogenesis.

There may be a significant reproductive recurrence risk in an individual with segUPD. There are multiple studies supporting this possibility, with 3 of these supporting a possible "hot-spot" involving terminal 11q Jacobsen syndrome (JS) related deletions [29-31].

Multiple studies offer compelling corroborative evidence for both a high incidence of 11q deletion rescue and associated germ cell mosaicism [29-31]. Johnson, et al. report two fraternal brothers with the same JSrelated deletion detected, although one was mosaic for the deletion. The maternal blood SNP microarray analysis revealed a copy-neutral, non-mosaic $\mathrm{ROH}$, coinciding with the deleted region in her sons. SegUPD11 was confirmed in the mother and an additional maternal fibroblast CMA revealed mosaicism both for the deletion and segUPD. Not surprisingly, mild JS symptoms were present in the maternal clinical evaluation. Thus, this study suggests a strong predilection to 11q deletion correction, since both mother and son had 11q correction with clinical variability. In addition, the study illustrates variable tissue-specific selection and confirms that the correction process may not include oocytes. Gonadal mosaicism occurs either because of uncorrected gametes from meiotic lesions or from gametes with somatically derived lesions, differentiable based on the presence/absence of heterozygote alleles in parental testing.

\section{SegUPD associated with triplication}

A distinct subset of 17 cases showed terminal segUPD located contiguous to triplications (Table 3). Contrary to the usual heterozygote allele-specific dosage patterns found in nearly all triplications (3:1 only or both 3:1 and 2:2 ratios), the CMAs in these cases demonstrate an exclusive 2:2 (AA; BB) allele pattern, indicating that the two extra copies are duplicates from each 
parental haplotype. Since FISH studies confirmed that the triplication was present in a single homologue with an inverted middle copy, one of the tandem copies had to have originated from the other parental homologue. This genomic rearrangement, has been attributed to mitotic recombination secondary to postzygotic template switching mediated microhomology break induced repair (MMBIR) [20, 32-35]. Our evidence supports the assertion that these rearrangements arise through correction of the relatively common class of meiotic rearrangements with inverted duplications contiguous with terminal deletions [36, 37]. This mechanism is supported by the mosaicism detected in an analysis of a fetal loss, in which an intermediate allele dosage plot suggested a mixture of two cell lines: one with an inverted duplication contiguous with a terminal deletion of $8 \mathrm{p}$ and the other, in which a triplication and terminal segUPD replaced the duplication and deletion (Case 46). Since the distal end of the duplication is inverted relative to the normal homologue, it is reasonable that microhomology mediates homologue strand annealing, which has been shown by breakpoint junction sequencing $[33,38]$ between the normal homologue and the distal end of the inverted duplication (Fig. 16). This would provide a telomere necessary for chromosome stability and provide a more viable deletion correction at the expense of adding an additional copy of the duplicated region.

\section{Mosaic SegUPD}

Mosaic segUPD is indicated by the presence of a subpopulation of cells with homozygosity within a specific terminal region (Fig. 3D) that arises in post-zygotic development. Expansion of a segUPD cell population may be random, secondary to an early developmental origin with no apparent advantage over the original normal cells. Alternatively, the cell population may be expanding through an advantage provided by a "driver" gene rendered homozygous in the segUPD interval, as in BWS.

Five cases in this cohort (cases 17, 21, 22, 32, and 33) have centromeric heterochromatin mitotic recombination initiation sites that have been considered predisposed to breakage, which may account for the frequency seen in this study. A break at these sites may be an early somatic event involving loss of the whole arm. The mosaicism may be associated with correction of an early post-zygotic deletion with rapid loss of the deleted cell line. This would make clinical effects less likely, consistent with the lack of correlation of any of these cases with region-specific deletion symptoms.

Cases 8, 24 and 34 provide evidence for an expanding homozygous population. The $>26 \mathrm{Mb}$ region terminal $7 \mathrm{q}$ region detected in case 8 spanned too many genes to attempt to ascertain if there was a gene conversion "driver" mutation that might be linked to the cardiac defect observed. Gene sequencing would be very helpful in this type of study. Case 34, which showed two cell populations with distinct mitotic recombination sites and apparent segUPD on the long arm of chromosome 19, contained the POLD1 gene in the segUPD region, which is a candidate gene for the progeria-like phenotype [39, 40]. The progressive symptoms appear consistent with a selective somatic drive to an abnormal phenotype. Similar selective mechanisms have been shown in patients with Proteus syndrome and related disorders, in which somatic mutations within the $A K T$ gene, as well as other genes within the PI3-AKT pathway, confer a growth advantage [41]. There is ample precedent for this in cancer CMAs, which frequently show clonal evolution with homozygous conversions of heterozygous mutations [21]. Multiple subclones that exhibit independent initiation sites in the same chromosomal arm proximal to the mutation are also common. Single gene selection to a normal phenotype may be found in patients exhibiting ichthyosis with mottling due to dominant KRT1 and KRT10 mutations, in which numerous clones of normal skin arise because of increased viability of cells that have converted to the homozygous wild type gene $[23,25]$. These reports show that each of the normal skin foci demonstrated a different mitotic recombination initiation site proximal to the mutation in the chromosome arm, consistent with a high potential for numerous recombination events and little or no site bias.

Case 30 showed apparent rescue of a mosaic interstitial deletion of $15 q$ by the concomitant presence of three distinct cell populations with differing levels of homozygosity (Fig. 12). The percentages of residual deletion ( 25\%) and segUPD lines $(\sim 75 \%)$ suggest concurrent selection that resulted in the partial replacement of the original deletion line through ongoing somatic selective pressure for repair. This is analogous to a blood CMA from a patient with chronic lymphocytic leukemia (Fig. 19), in which a deletion of the MIR15/16 tumor suppressor has evolved to a homozygous loss by positive selection for two independent cell lines with separate mitotic recombination initiation sites resulting in bi-allelic loss. The genes responsible for the selection in case 30 are likely to be within the $15 \mathrm{q} 25.2$ microdeletion syndrome critical region at the center of the deletion interval. The proband phenotype is consistent with sustained microdeletion syndrome effects [42].

\section{Diagnostic and clinical considerations}

This study has numerous important implications for clinical diagnoses including: (1) terminal $\mathrm{ROH}$ associated with segUPD can arise secondarily to a variety of genomic imbalances, some of which may also have 


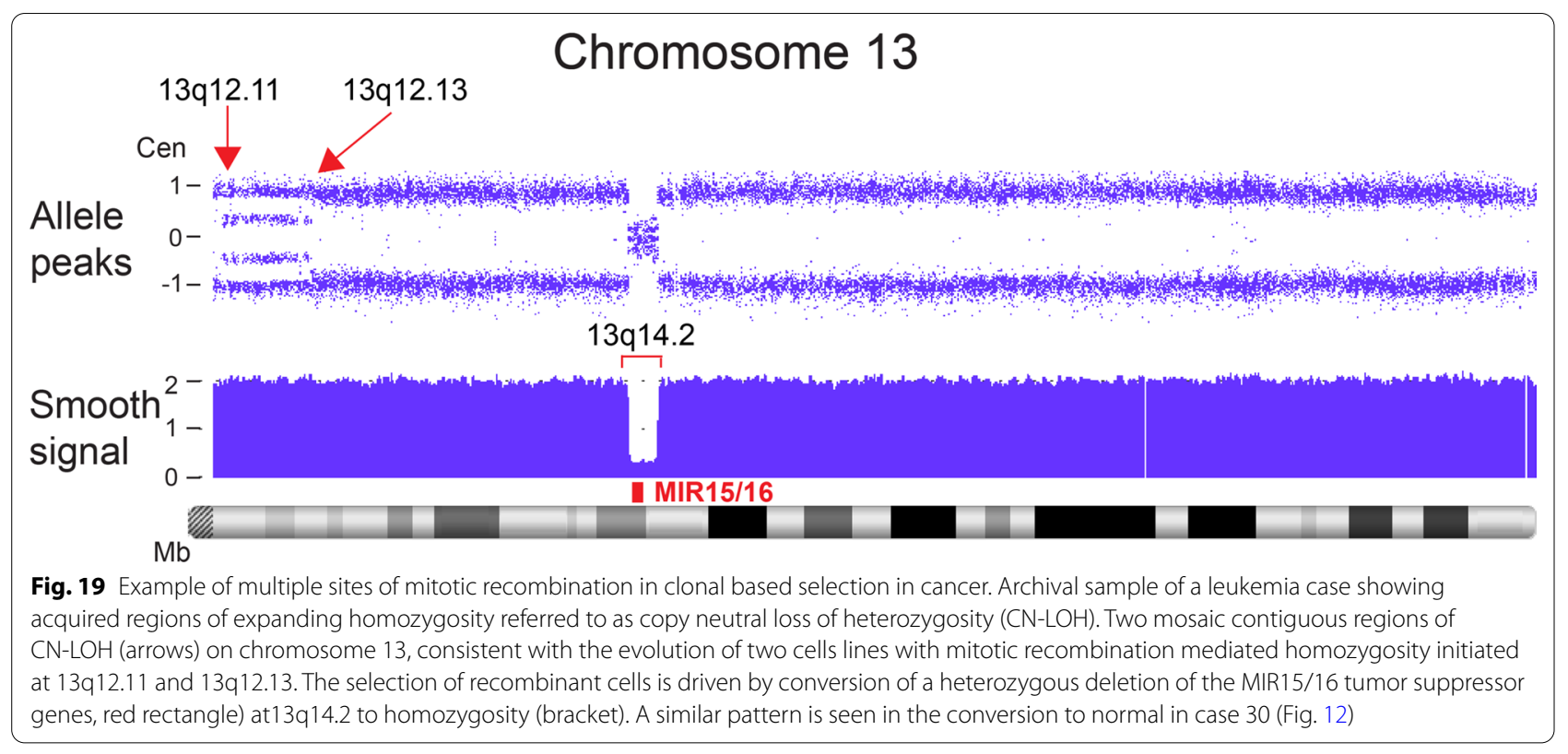

corrected in a carrier parent; (2) corrections are mediated by mitotic recombination that occurs at or proximal to the site of imbalance; (3) clinical effects in corrections of meiotic-derived imbalance are likely to depend on whether the imbalance was sustained in critical tissues during development, making the effects difficult to predict. Additionally, (4) studies of multiple tissues (e.g. buccal cells in addition to blood) may be required to reveal sustained imbalance; (5) mosaic segUPD cases that have progressive symptoms or can be shown to have arisen post-zygotically appear to be more likely mediated by gene-related homozygotic allele advantage; (6) it is likely that at least some cases of reproductive recurrence of the same alteration can be attributed to a parent with abnormal gametes that failed to correct; (7) there appear to be regional "hot spots" for corrections such as $1 \mathrm{p}$ and 11q, although evidence of this was not apparent in the UPD database [17]. The lack of examples in the database may be due to the bias for ascertainment of the reported cases for imprinted syndromes and recessive disorders with non-Mendelian inheritance. Our ascertainment is based on the presence of a terminal $\mathrm{ROH}$, which can be associated with a variety of clinical symptoms or an alteration detected in a different tissue or at a previous time in development.

Unfortunately, extended terminal $\mathrm{ROH}$ associated with segUPD may be reported as possible identity by descent or not noted at all if below the reporting criteria. A $5 \mathrm{Mb}$ reporting threshold has been recommended [12]. Therefore, terminal $\mathrm{ROH}$ should be considered for possible segUPD at sizes smaller than other reporting criteria and with appropriate molecular follow-up testing. Currently, whole exome sequencing methodologies aren't widely utilized for the detection of segUPD, but extended terminal allele homozygosity should be considered for followup trio analysis to effectively rule out segUPD by either whole exome sequencing or CMAs. That testing could be restricted to apparent hot spots like $1 \mathrm{p}$ and $11 \mathrm{q}$ that are known to have high frequencies of syndrome breakage $[43,44]$, terminal $\mathrm{ROH}$ greater than $\sim 5 \mathrm{Mb}$, and cases without obvious identity by descent. The frequency of segUPD is not known, but mosaic segUPD in younger individuals has been estimated at almost $0.5 \%[45,46]$. Recent sequencing studies have shown an overall prevalence of whole chromosome UPD as high as 1 in 176 in patients with developmental delay and 1 in 2000 of general population live births $[8,9]$. It is likely that the incidence of these cases will increase since NIPT studies are able to detect early evidence of imbalances, which in some cases, may be subsequently corrected leaving the associated terminal $\mathrm{ROH}$. These cases present genetic counseling challenges because it will not be known whether the original imbalance will be associated with clinical effects in the fetus or the correction has occurred early enough to offer a complete clinical rescue.

Clearly, NIPT results that are discordant with subsequent testing provide an excellent opportunity to identify dynamic placental-fetal corrections. We have recently reported 3 additional discordant cases associated with segUPD [47]. Many of these aberrations are restricted to the placenta, but some also show residual fetal mosaicism in follow-up analyses.

These examples of NIPT genomic corrections indicate that changes may need to be made in parental follow-up 
testing. We propose that following normal parental follow-up karyotyping (consistent with a de novo rearrangement in their child), SNP microarray testing could be performed in the region of imbalance to exclude segmental UPD in the parents and the associated high risk of recurrence for accurate prenatal counseling. If half the oocytes in a female with segUPD associated rescue of a meiotic genomic imbalance are abnormal, the risk of recurrence in future offspring may be as high as $50 \%$. It is possible that paternally derived imbalances may not be subject to germ cell correction exclusion as with oocytes. Further studies are necessary to determine the overall incidence of corrections, to confirm hot spots for corrections such as the $1 \mathrm{p}$ and $11 \mathrm{q}$ terminal regions, and to ascertain if paternal germ cells have the potential to correct. Selection-based somatic recombination-mediated repair may be a relatively frequent occurrence with patent reproductive risk and may explain the etiology of clinical phenotypes in more patients than currently known.

\begin{abstract}
Abbreviations
AF: Amniotic fluid; AMA: Advanced maternal age; arr: Microarray; AV: Atrioventricular; BWS: Beckwith-Wiedemann syndrome; Cen: Centromere; cfDNA: Cell-free deoxyribonucleic acid (DNA); CMA: Chromosomal microarray analysis; CN-LOH: Copy-neutral loss of heterozygosity; CVS: Chorionic villus sample; der: Derivative; DNA: Deoxyribonucleic acid; EEG: Electroencephalogram; FISH: Fluorescence in situ hybridization; JS: Jacobsen syndrome; Mat: Maternal; Mb: Megabases; MMBIR: Microhomology break induced repair; MSS: Maternal serum screening; NA: Not available; NB: Newborn; NIPT: Non-invasive prenatal testing; NT: Nuchal translucency; Pat: Paternal; POC: Products of conception (tissue); pter: p arm terminus; qter: q arm terminus; ROH: Run(s) of homozygosity; segUPD: Segmental uniparental disomy; SNP: Single nucleotide polymorphism; t: Translocation; Tel: Telomere; UPD: Uniparental disomy; VSD: Ventricular septal defect.
\end{abstract}

\section{Supplementary Information}

The online version contains supplementary material available at https://doi. org/10.1186/s13039-021-00555-0.

Additional file 1. Figure S1. SegUPD parent of origin study of case 1. Figure S2. SegUPD parent of origin study of case 6. Figure S3. SegUPD parent of origin study of case 9 . Figure S4. SegUPD parent of origin study of case 12 (A: Microarray indicating large $\mathrm{ROH}$ on chromosome 15; B: SNP analysis confirming paternal segUPD of q15.3->qter).

\section{Acknowledgements}

Not applicable.

\section{Authors' contributions}

P.P. collected and analyzed the data, contributed figures and was a major contributor in writing the manuscript. C.K. organized the data, designed and edited many figures and edited and formatted the manuscript. S.H. contributed the data and analysis for case 6. S.C. contributed data for cases 3 and 5. S.S. analyzed the data and reviewed the manuscript. A.P. collected and analyzed the data, contributed figures and was a major contributor in writing the manuscript. All authors read and approved the final manuscript.

\section{Funding}

The study was funded by Laboratory Corporation of America. Study design, data collection, data management, data analyses, and decision to submit the report for publication, manuscript preparation, and review were sponsored by Laboratory Corporation of America.

Availability of data and materials

Tables and supplementary data are included in the manuscript.

\section{Declarations}

Ethics approval and consent to participate

Informed consent was received.

\section{Consent for publication}

Not applicable.

\section{Competing interests}

Authors PP, CK, SC, SS, and AP are employees of Laboratory Corporation of America with option to hold stock. SH is employed by University of South Florida.

\section{Author details}

${ }^{1}$ Cytogenetics Department, Laboratory Corporation of America, Research Triangle Park, NC 27709, USA. ${ }^{2}$ Morsani College of Medicine, University of South Florida, Tampa, FL 33612, USA.

Received: 24 March 2021 Accepted: 22 June 2021

Published online: 20 July 2021

\section{References}

1. Engel E. A new genetic concept: uniparental disomy and its potential effect, isodisomy. Am J Med Genet. 1980;6(2):137-43.

2. Papenhausen P, Schwartz S, Risheg H, Keitges E, Gadi I, Burnside RD, Jaswaney V, Pappas J, Pasion R, Friedman K, Tepperberg J. UPD detection using homozygosity profiling with a SNP genotyping microarray. Am J Med Genet A. 2011;155(4):757-68.

3. Kearney HM, Kearney JB, Conlin LK. Diagnostic implications of excessive homozygosity detected by SNP-based microarrays: consanguinity, uniparental disomy, and recessive single-gene mutations. Clin Lab Med. 2011;31(4):595-613.

4. Lapunzina P, Monk D. The consequences of uniparental disomy and copy number neutral loss-of-heterozygosity during human development and cancer. Biol Cell. 2011;103(7):303-17.

5. Schollen E, Grünewald S, Keldermans L, Albrecht B, Körner C, Matthijs G. CDG-Id caused by homozygosity for an ALG3 mutation due to segmental maternal isodisomy UPD3 (q21. 3-qter). Eur J Med Genet. 2005:48(2):153-8.

6. Robinson WP. Mechanisms leading to uniparental disomy and their clinical consequences. BioEssays. 2000;22(5):452-9.

7. Scuffins J, Keller-Ramey J, Dyer L, Douglas G, Torene R, Gainullin V, Juusola $J$, Meck J, Retterer K. Uniparental disomy in a population of 32,067 clinical exome trios. Genet Med. 2021;25:1-7.

8. Nakka P, Smith SP, O'Donnell-Luria AH, McManus KF, Agee M, Auton A, Bell RK, Bryc K, Elson SL, Fontanillas P, Furlotte NA. Characterization of prevalence and health consequences of uniparental disomy in four million individuals from the general population. Am J Hum Genet. 2019;105(5):921-32.

9. Yauy K, de Leeuw N, Yntema HG, Pfundt R, Gilissen C. Accurate detection of clinically relevant uniparental disomy from exome sequencing data. Genet Med. 2020;22(4):803-8.

10. Cooper WN, Curley R, Macdonald F, Maher ER. Mitotic recombination and uniparental disomy in Beckwith-Wiedemann syndrome. Genomics. 2007:89(5):613-7.

11. Liehr T. Cytogenetic contribution to uniparental disomy (UPD). Mol Cytogenet. 2010;3(1):1-7. 
12. Hoppman N, Rumilla K, Lauer E, Kearney H, Thorland E. Patterns of homozygosity in patients with uniparental disomy: detection rate and suggested reporting thresholds for SNP microarrays. Genet Med. 2018;20(12):1522-7.

13. Del Gaudio D, Shinawi M, Astbury C, Tayeh MK, Deak KL, Raca G. Diagnostic testing for uniparental disomy: a points to consider statement from the American College of Medical Genetics and Genomics (ACMG). Genet Med. 2020;22(7):1133-41.

14. Moynahan ME, Jasin M. Mitotic homologous recombination maintains genomic stability and suppresses tumorigenesis. Nat Rev Mol Cell Biol. 2010;11(3):196-207.

15. Eggermann T, Mergenthaler S, Eggermann K, Albers A, Linnemann K, Fusch C, Ranke MB, Wollmann HA. Identification of interstitial maternal uniparental disomy (UPD) (14) and complete maternal UPD (20) in a cohort of growth retarded patients. J Med Genet. 2001;38(2):86-9.

16. Martin RA, Sabol DW, Rogan PK. Maternal uniparental disomy of chromosome 14 confined to an interstitial segment (14q23-14q24. 2). J Med Genet. 1999;36(8):633-6.

17. Liehr T. Cases with uniparental disomy. http://cs-tl.de/DB/CA/UPD/0-Start. html. Accessed 04 May 2021.

18. Jensen TJ, Zwiefelhofer T, Tim RC, Džakula Ž, Kim SK, Mazloom AR, Zhu Z, Tynan J, LuT, McLennan G, Palomaki GE. High-throughput massively parallel sequencing for fetal aneuploidy detection from maternal plasma. PLOS ONE. 2013;8(3):e57381.

19. Lefkowitz RB, Tynan JA, Liu T, Wu Y, Mazloom AR, Almasri E, Hogg G, Angkachatchai V, Zhao C, Grosu DS, McLennan G. Clinical validation of a noninvasive prenatal test for genomewide detection of fetal copy number variants. Am J Obstet Gynecol. 2016;215(2):227-e1.

20. Papenhausen PR, Kelly CA, Zvereff V, Schwartz S. Four-copy number intervals in SNP microarray analysis: unique patterns and positions. Cytogenet Genome Res. 2014;144(2):92-103.

21. O'Keefe C, McDevitt MA, Maciejewski JP. Copy neutral loss of heterozygosity: a novel chromosomal lesion in myeloid malignancies. Blood. 2010;115(14):2731-9.

22. Cajaiba MM, Witchel S, Madan-Khetarpal S, Hoover J, Hoffner L, Macpherson T, Surti U. Prenatal diagnosis of trisomy 6 rescue resulting in paternal UPD6 with novel placental findings. Am J Med Genet A. 2011;155(8):1996-2002.

23. Choate KA, Lu Y, Zhou J, Choi M, Elias PM, Farhi A, Nelson-Williams C, Crumrine D, Williams ML, Nopper AJ, Bree A. Mitotic recombination in patients with ichthyosis causes reversion of dominant mutations in KRT10. Science. 2010;330(6000):94-7.

24. Kiraly O, Gong G, Olipitz W, Muthupalani S, Engelward BP. Inflammationinduced cell proliferation potentiates DNA damage-induced mutations in vivo. PLoS Genet. 2015;11(2):e1004901

25. Choate KA, Lu Y, Zhou J, Elias PM, Zaidi S, Paller AS, Farhi A, NelsonWilliams C, Crumrine D, Milstone LM, Lifton RP. Frequent somatic reversion of KRT1 mutations in ichthyosis with confetti. J Clin Investig. 2015;125(4):1703-7.

26. dos Santos A, Campagnari F, Krepischi ACV, Ribeiro Câmara ML, de Arruda Brasil RDCE, Vieira L, Vianna-Morgante AM, Otto PA, Pearson PL, Rosenberg C. Insight into the mechanisms and consequences of recurrent telomere capture associated with a sub-telomeric deletion. Chromosom Res. 2018;26(3):191-8. https://doi.org/10.1007/s10577-018-9578-z.

27. Cohen AS, Wilson SL, Trinh J, Ye XC. Detecting somatic mosaicism: considerations and clinical implications. Clin Genet. 2015;87(6):554-62.

28. Kucińska-Chahwan A, Bijok J, Dąbkowska S, Jóźwiak A, Ilnicka A, Nowakowska B, Jakiel G, Roszkowski T. Targeted prenatal diagnosis of PallisterKillian syndrome. Prenat Diagn. 2017;37(5):446-52.

29. Johnson JP, Haag M, Beischel L, McCann C, Phillips S, Tunby M, Hansen J, Schwanke C, Reynolds JF.'Deletion rescue' by mitotic 11 q uniparental disomy in a family with recurrence of 11 q deletion Jacobsen syndrome. Clin Genet. 2014;85(4):376-80

30. Kawai M, Tsutsumi M, Suzuki F, Sameshima K, Dowa Y, Kyoya T, Inagaki $\mathrm{H}$, Kurahashi $\mathrm{H}$. Two siblings with 11 qter deletion syndrome that had been rescued in their mother by uniparental disomy. Eur J Med Genet. 2019;62(3):224-8.

31. Afifi HH, Zaki MS, El-Gerzawy AM, Kayed HF. Distal 11 q monosomy syndrome: a report of two Egyptian sibs with normal parental karyotypes confirmed by molecular cytogenetics. Genet Couns. 2008;19(1):47.
32. Bonaglia MC, Giorda R, Beri S, Bigoni S, Sensi A, Baroncini A, Capucci A, De Agostini C, Gwilliam R, Deloukas P, Dunham I. Mosaic 22q13 deletions: evidence for concurrent mosaic segmental isodisomy and gene conversion. Eur J Hum Genet. 2009;17(4):426-33.

33. Carvalho CM, Pfundt R, King DA, Lindsay SJ, Zuccherato LW, Macville MV, Liu P, Johnson D, Stankiewicz P, Brown CW, Study DD. Absence of heterozygosity due to template switching during replicative rearrangements. Am J Hum Genet. 2015;96(4):555-64.

34. Sahoo T, Wang JC, Elnaggar MM, Sanchez-Lara P, Ross LP, Mahon LW, Hafezi K, Deming A, Hinman L, Bruno Y, Bartley JA. Concurrent triplication and uniparental isodisomy: evidence for microhomology-mediated break-induced replication model for genomic rearrangements. Eur J Hum Genet. 2015;23(1):61-6.

35. Kohmoto T, Okamoto N, Naruto T, Murata C, Ouchi Y, Fujita N, Inagaki H, Satomura S, Okamoto N, Saito M, Masuda K. A case with concurrent duplication, triplication, and uniparental isodisomy at 1q42. 12-qter supporting microhomology-mediated break-induced replication model for replicative rearrangements. Mol Cytogenet. 2017;10(1):1-8.

36. Hermetz KE, Newman S, Conneely KN, Martin CL, Ballif BC, Shaffer LG, Cody JD, Rudd MK. Large inverted duplications in the human genome form via a fold-back mechanism. PLoS Genet. 2014;10(1):e1004139.

37. Zuffardi O, Bonaglia M, Ciccone R, Giorda R. Inverted duplications deletions: underdiagnosed rearrangements? Clin Genet. 2009;75(6):505-13.

38. Kato T, Inagaki H, Miyai S, Suzuki F, Naru Y, Shinkai Y, Kato A, Kanyama K, Mizuno S, Muramatsu Y, Yamamoto T. The involvement of U-type dicentric chromosomes in the formation of terminal deletions with or without adjacent inverted duplications. Hum Genet. 2020;139:1417-27.

39. Shastry S, Simha V, Godbole K, Sbraccia P, Melancon S, Yajnik CS, Novelli G, Kroiss M, Garg A. A novel syndrome of mandibular hypoplasia, deafness, and progeroid features associated with lipodystrophy, undescended testes, and male hypogonadism. J Clin Endocrinol Metab. 2010;95(10):E192-7.

40. Weedon MN, Ellard S, Prindle MJ, Caswell R, Allen HL, Oram R, Godbole K, Yajnik CS, Sbraccia P, Novelli G, Turnpenny P. An in-frame deletion at the polymerase active site of POLD1 causes a multisystem disorder with lipodystrophy. Nat Genet. 2013;45(8):947-50.

41. Keppler-Noreuil KM, Parker VE, Darling TN, Martinez-Agosto JA. Somatic overgrowth disorders of the PI3K/AKT/mTOR pathway and therapeutic strategies. Am J Med Genet Part C Semin Med Genet. 2016;172(4):402-21.

42. Burgess T, Brown NJ, Stark Z, Bruno DL, Oertel R, Chong B, Calabro V, Kornberg A, Sanderson C, Kelly J, Howell KB. Characterization of core clinical phenotypes associated with recurrent proximal 15q25. 2 microdeletions. Am J Med Genet Part A. 2014;164(1):77-86.

43. Shaffer LG, Lupski JR. Molecular mechanisms for constitutional chromosomal rearrangements in humans. Annu Rev Genet. 2000;34(1):297-329.

44. Ballif BC, Yu W, Shaw CA, Kashork CD, Shaffer LG. Monosomy 1 p36 breakpoint junctions suggest pre-meiotic breakage-fusion-bridge cycles are involved in generating terminal deletions. Hum Mol Genet. 2003;12(17):2153-65.

45. Sasaki K, Mishima H, Miura K, Yoshiura KI. Uniparental disomy analysis in trios using genome-wide SNP array and whole-genome sequencing data imply segmental uniparental isodisomy in general populations. Gene. 2013;512(2):267-74

46. Laurie CC, Laurie CA, Rice K, Doheny KF, Zelnick LR, McHugh CP, Ling $H$, Hetrick KN, Pugh EW, Amos C, Wei Q. Detectable clonal mosaicism from birth to old age and its relationship to cancer. Nat Genet. 2012;44(6):642-50.

47. Caldwell S, Sagaser K, Nelson Z, Frey J, Wardrop J, Boomer T, McCullough $R$, Schwartz S. Deletion rescue resulting in segmental homozygosity: a mechanism underlying discordant NIPT results. Am J Med Genet A. 2020;182(11):2666-70.

\section{Publisher's Note}

Springer Nature remains neutral with regard to jurisdictional claims in published maps and institutional affiliations. 